This is the Author's Accepted Manuscript of the following article: Lostalé-Seijo, I., \& Montenegro, J. (2018). Synthetic materials at the forefront of gene delivery. Nature Reviews Chemistry. doi: 10.1038/s41570-018-0039-1

\title{
1 Synthetic Materials at the Forefront of Gene Delivery
}

\author{
2 Irene Lostalé-Seijo ${ }^{\dagger}$, \& Javier Montenegro ${ }^{\dagger *}$ \\ $3{ }^{\dagger}$ Centro Singular de Investigación en Química Biolóxica e Materiais Moleculares (ClQUS), Departamento de Química Orgánica, \\ 4 Universidade de Santiago de Compostela, 15782 Santiago de Compostela, Spain. *e-mail: javier.montenegro@usc.es.
}

5

6

7

8

9

10

11

12

13

14

15

16

17

18

19

20

21

22

23

24

25

26

27

\begin{abstract}
The delivery of materials for genetic engineering with transitory activity constitutes a promising field in biology and medicine with potential applications in the treatment of disease, from cancer and infectious diseases to inheritable disorders. The possibility to restore the expression of a missing protein, the potential correction of the splicing of defective genes, or the silencing or modulation of the expression of other genes constitute powerful tools that will have a great impact in the future of biology and medicine. Impressive progress has been made in the last decade, with several products reaching the market as novel technologies for gene editing emerge. However, the transference of these technologies to functional therapies is hindered by the suboptimal performance of vehicles in capturing, protecting and delivering the corresponding nucleotide cargoes with safety and efficacy. Chemistry and the chemical sciences will play a key role in the development of the innovative synthetic materials that will overcome the upcoming challenges of the next generation gene delivery therapies and protocols. In this review we address the newest chemical advances in the production of materials at the forefront of nucleotide cell delivery and gene therapy.
\end{abstract}

\section{Introduction}

Chemistry and molecular biology have always been involved in the development of new technologies with potential therapeutic applications. DNA automated synthesis ${ }^{1}$ has been essential for PCR $^{2}$, or site-directed mutagenesis ${ }^{3}$. These have allowed the generation of optimized fluorescent proteins ${ }^{4}$, phage display technology ${ }^{5}$, unnatural amino acids incorporation into proteins ${ }^{6}$, catalytic antibodies ${ }^{7,8}$ and synthetic genomes ${ }^{9-11}$. Among all of these discoveries and techniques, genetic engineering and gene therapy constitute one of the most promising technologies for the treatment of disease and for the future of human health ${ }^{12-14}$. The use of nucleic acids as therapeutic agents to repair a protein deficiency or to modulate gene expression has a great potential not only for the treatment of inherited disorders, but also in the treatment of acquired diseases through their utilization as DNA vaccines, antiviral therapies and cancer immunotherapy ${ }^{13}$ (TABLE 1). However, the growth of the expectations in gene therapy and medicine have sometimes been dramatically crushed by the delivery problem ${ }^{15}$. Nucleic acids are negatively charged and are occasionally very unstable molecules and thus their intracellular delivery, at the right place at the right moment, still constitutes a challenge for synthetic chemistry, materials science and biotechnology.

A gene vector has to overcome different barriers before the successful delivery of its cargo (FIG. 1; TABLE 2). First, the nucleotide cargo should be protected from degradation, which is usually achieved by complexation or encapsulation in different structures ${ }^{16}$. The size and charge of these complexes has to be controlled as it affects uptake efficiency and bio-distribution, as too large or too small particles can be cleared by the mononuclear phagocyte system, the liver or the kidneys ${ }^{16}$. In systemic delivery, molecules larger than individual oligonucleotides cannot cross the endothelial barrier except for tissues with fenestrated or leaky vasculature ${ }^{17}$. Improving carrier selectivity by conjugation of the vector with targeting molecules can increase selectivity towards targeted cells increasing uptake and decreasing off-target effects ${ }^{17}$. Finally, vector particles have to translocate the plasma membrane, avoid endosomal entrapment and, in some cases, cross the nuclear envelope ${ }^{16}$. Moreover, the nucleotide cargo has to be released from the transported complexes to be free to interact with its target or be recognized by the cellular elements required for silencing, transcription or translation. Therefore, the delivery efficiency is not only a question of plasma membrane translocation and cellular internalization. The ideal gene carrier should be able to deliver different nucleic acids, protect the cargo from nucleases, avoid fast clearance, toxicity, and immune detection, prevent non-specific interactions with proteins and non-target cells, reach the cells of interest, escape the endosome, release the cargo and, when necessary, transport the cargo into the nucleus (TABLE 2) ${ }^{16,18,19}$. This is obviously not a simple task for synthetically scalable materials but the latest achievements in the field point to a promising future for the wide variety of non-viral vectors.

Viruses function as natural gene carriers as they are able to bind the cell membrane, internalize in the cell, and escape the endosome to reach the cytosol. As viruses survival requires the efficient delivery of their own genetic material into cells, they have been artificially manipulated for therapeutic gene transfection ${ }^{20,21}$. Therefore, some modified viral vectors have been approved for the treatment of human disease, such as Glybera for lipoprotein lipase deficiency $^{22}$, Gendicine for cancer treatment ${ }^{23}$, or Luxturna for retinal dystrophy ${ }^{24}$. However, viruses and derived materials present drawbacks, mainly related with their low cargo capacity and their immunogenicity that can cause fatal adverse reactions or abrogate their activity, or require additional immunosuppresive therapy ${ }^{14,25}$. Furthermore, 

strongly complicates their real applicability in gene therapy. For instance, Glybera has been withdrawn from the market due to the high production costs and lack of demand ${ }^{26}$.

The combination of synthetic chemistry and molecular biology has been widely explored for the development of artificial carriers that could accomplish efficient and selective intracellular gene delivery ${ }^{1827-30}$. Traditional non-viral vectors showed low efficiency due to low cell selectivity as well as endosomal entrapment. Additionally, most of the delivery studies are performed on monolayers of immortal cell lines that usually contain alterations in DNA/RNA sensing or survival pathways, which can overestimate their efficiency when transferred to in vivo ${ }^{31}$. Nevertheless, impressive conceptual advances in synthetic gene vehicles have emerged in the last few years and several compounds have shown good activity, not only in vitro but also in vivo. Nucleotide chemical modifications have delivered a new set of artificial nucleic acid analogues with higher stability, improved activity and lower immunogenicity ${ }^{32}$. Additionally, the current covalent and supramolecular synthetic tools allow the preparation of an unlimited number of new compounds that can be applied for the delivery of bioactive nucleotides. Nowadays, several formulations for gene-based therapies are reaching the $\operatorname{clinic}^{33}$. Although viral vectors predominate in the medical applications of gene therapy ${ }^{34}$, synthetic vectors are becoming a real alternative in nucleotide-mediated therapeutics. For instance, naked antisense phosphorothioates have been recently approved for human use ${ }^{35}$, non-viral siRNA delivery systems are being tested for cancer treatment ${ }^{36,37}$, and Patisiran, a lipid nanoparticle for the delivery of siRNA for the treatment of hereditary transthyretin-mediated amyloidosis, has recently finished phase 3 studies $^{38}$. This review will address the latest advances in non-viral gene delivery and we have sorted these synthetic carriers according to their chemical nature in order to highlight the importance of their molecular structure and connect this structural information to its particular functional application (TABLE 2).

\begin{tabular}{|c|c|c|c|}
\hline Cargo & Description & Site of Activity & Function \\
\hline $\begin{array}{l}\text { Plasmid } \\
\text { Minicircles }\end{array}$ & $\begin{array}{l}\text { Large circular dsDNA molecules (several } \\
\text { kb). Minicircles are usually smaller (no } \\
\text { bacterial backbone). } \\
\text { Need to reach the nucleus to be transcribed. } \\
\text { Half-life in serum: } 10-20 \text { min }^{200} \text {. } \\
\text { Active in cells: some constructions can be } \\
\text { active for months or years }{ }^{19} \text {. }\end{array}$ & Nucleus & $\begin{array}{l}\text { Expression of proteins to restore a } \\
\text { function or to develop an immune } \\
\text { response against it. } \\
\text { Expression of regulatory RNAs. } \\
\text { Some risk of insertional mutagenesis by } \\
\text { recombination with cellular DNA. }\end{array}$ \\
\hline $\begin{array}{l}\text { mRNA } \\
\text { Replicon RNA }\end{array}$ & $\begin{array}{l}\text { Large ssRNA molecules: several kb, } \\
\text { typically mRNA < } 10 \mathrm{~kb} \text {; replicon }>10 \mathrm{~kb} \\
\text { (includes gene sequence and non-structural } \\
\text { replicase genes). } \\
\text { Secondary structure may impact translation } \\
\text { efficiency } \\
\text { Half-life in serum: seconds } \\
\text { Active in cells: from minutes to days }\end{array}$ & Cytosol & $\begin{array}{l}\text { Protein expression to restore function or } \\
\text { to develop immune response against it. } \\
\text { Replicon self-amplifies and extends the } \\
\text { time protein is being expressed. } \\
\text { No risk of recombination with cellular } \\
\text { genome. }\end{array}$ \\
\hline $\begin{array}{l}\text { Antisense } \\
\text { oligonucleotides } \\
\text { Splice correcting } \\
\text { oligonucleotides }\end{array}$ & $\begin{array}{l}\text { Short DNA, RNA or analogues (15-30 nt) } \\
\text { Half-life dependent on the chemistry of the } \\
\text { backbone. }\end{array}$ & Cytosol/Nucleus & $\begin{array}{l}\text { Mask alternative splice sites to produce } \\
\text { the desired mRNA isoform (splice } \\
\text { correcting oligonucleotides). } \\
\text { Degradation of mRNA after forming } \\
\text { DNA/RNA duplexes by RNaseH } \\
\text { (antisense oligonucleotides). } \\
\text { Inhibition of mRNA translation by } \\
\text { steric hindrance (antisense } \\
\text { oligonucleotides). }\end{array}$ \\
\hline $\begin{array}{l}\text { Short regulatory } \\
\text { RNAs (siRNA, } \\
\text { miRNA...) }\end{array}$ & $\begin{array}{l}\text { Short ( 21-22 bp) } \\
\text { Half-life in serum: minutes, but it can be } \\
\text { increased with backbone modifications }{ }^{203} \\
\text { Active in cells: from days to months, } \\
\text { depending on the mechanism of action }{ }^{188}\end{array}$ & Cytosol/Nucleus & $\begin{array}{l}\text { Directs RISC complex to specific } \\
\text { mRNAs for degradation (siRNA, } \\
\text { cytosolic) } \\
\text { Induces long-term silencing by DNA } \\
\text { methylation (siRNA, nucleus). } \\
\text { Regulates mRNA stability or translation } \\
\text { (miRNA, cytosolic). } \\
\text { Induces chromatin reorganization } \\
\text { (miRNA, nucleus). }\end{array}$ \\
\hline $\begin{array}{l}\text { DNazyme, } \\
\text { RNazyme, } \\
\text { MNazyme }\end{array}$ & $\begin{array}{l}\text { Short ( } ~ 50-150 \mathrm{nt}) \text {, typically with } \\
\text { complicated secondary structures. } \\
\text { Half-life dependent on the chemistry of the } \\
\text { backbone }\end{array}$ & Cytosol/Nucleus & $\begin{array}{l}\text { Nucleic acids with enzymatic activity, } \\
\text { usually used as site specific nucleases. } \\
\text { Composed of a single strand of DNA } \\
\text { (DNazymes), RNA (RNazymes), or } \\
\text { multiple strands (MNazymes). }\end{array}$ \\
\hline
\end{tabular}




\begin{tabular}{|c|c|c|c|}
\hline Barrier & Strategy & Examples & Ref \\
\hline \multirow{5}{*}{$\begin{array}{l}\text { Nuclease } \\
\text { degradation }\end{array}$} & Backbone modification & PS bonds and 2' modifications to reduce hydrolysis & $35,39-43$ \\
\hline & $\begin{array}{l}\text { Covalent attachment of } \\
\text { molecules }\end{array}$ & PEG brushes (pacDNA) & 56,57 \\
\hline & \multirow[t]{3}{*}{ Non-covalent interactions } & Masking of siRNA by dsRNA binding proteins & 77,78 \\
\hline & & Inhibitory local high salt concentration in SNAs & $185-187,190-193$ \\
\hline & & Complexation or encapsulation with different carriers & See section 2.3 \\
\hline \multirow{9}{*}{$\begin{array}{l}\text { Complexation } \\
\text { and particle } \\
\text { formation }\end{array}$} & $\begin{array}{l}\text { Self-assembling } \\
\text { oligonucleotides }\end{array}$ & PS-tcDNA & 40 \\
\hline & Nucleic acid nanoparticles & DNA or RNA nanoparticles generated by RCA or RCT. & 58,59 \\
\hline & \multirow{2}{*}{$\begin{array}{l}\text { Covalent attachment to } \\
\text { polymers or nanoparticles }\end{array}$} & PEG-Brushes (pacDNA) & 56,57 \\
\hline & & Spherical nucleic acids & $185-187,190-193$ \\
\hline & \multirow{2}{*}{$\begin{array}{l}\text { Increased affinity for } \\
\text { nucleic acids }\end{array}$} & Modification of peptides with guanidiniocarbonyl pyrrole & \\
\hline & & Polymer modification with zinc dipicolylamine & 138 \\
\hline & \multirow[t]{2}{*}{$\begin{array}{l}\text { Improved encapsulation } \\
\text { methods }\end{array}$} & $\begin{array}{l}\text { Enhancing encapsulation efficiency of exosomes by } \\
\text { cholesterol modified siRNA }\end{array}$ & 126,127 \\
\hline & & High-yield encapsulation of siRNA in silica nanoparticles & 194 \\
\hline & Other strategies & Complexation or encapsulation with different carriers & See section 2.3 \\
\hline \multirow{12}{*}{$\begin{array}{l}\text { Systemic } \\
\text { distribution, } \\
\text { targeting and } \\
\text { toxicity } \\
\text { problems }\end{array}$} & Increasing circulation time & Enhancing interaction with albumin or antibodies & $79-83$ \\
\hline & \multirow[t]{4}{*}{ Reducing toxicity } & Degradable nanoneedles to reduce inflammatory response & 67 \\
\hline & & $\begin{array}{l}\text { Avoiding immune recognition of VLPs by shielding with } \\
\text { polymers }\end{array}$ & 74 \\
\hline & & Slow release of polyplexes from silica nanoparticles. & 195 \\
\hline & & Fluorination of polymers and dendrimers & $145-147$ \\
\hline & \multirow{7}{*}{$\begin{array}{l}\text { Targeting to the desired } \\
\text { cells or tissue }\end{array}$} & Recognition of membrane proteins by aptamers & $49-51,58,119$ \\
\hline & & Recognition of membrane proteins by antibodies & 82,83 \\
\hline & & $\begin{array}{l}\text { Recognition of ASGPR by tri-antennary- } N \text {-acetyl } \\
\text { galactosamine }\end{array}$ & $52-54$ \\
\hline & & $\begin{array}{l}\text { Spatial control of the delivery by using ultrasound } \\
\text { triggered release of microbubbles or liposomes }\end{array}$ & 68-70 \\
\hline & & Targeting peptides (RGD) & $130,131,182$ \\
\hline & & $\begin{array}{l}\text { Modification of the natural target of VLP and exosomes } \\
\text { by surface modifications }\end{array}$ & $73,75,76,125$ \\
\hline & & Recognition of specific cells with artificial modifications & 107,109 \\
\hline \multirow{20}{*}{$\begin{array}{l}\text { Cellular } \\
\text { uptake and } \\
\text { release of the } \\
\text { cargo }\end{array}$} & \multirow[t]{2}{*}{ Backbone modifications } & Gymnosis of phosphorothioate nucleotides & $35,39-43$ \\
\hline & & Esterification to facilitate membrane crossing & 48 \\
\hline & \multirow[t]{8}{*}{ Endosomal escape } & Physical methods & 66,67 \\
\hline & & Taking advantage of viral capsid proteins in VLP & $73,75,76$ \\
\hline & & Avoiding endocytic pathways (peptide CLIP6) & 88,89 \\
\hline & & Protonable peptides, foldamers and dendrimers & $84,94-96,152$ \\
\hline & & Ionizable lipids & $115,116,118$ \\
\hline & & Topology mediated fusion & $110-113$ \\
\hline & & pH triggered disassembly & $130-136,150$ \\
\hline & & Fluorination of polymers and dendrimers & $145-147$ \\
\hline & \multirow[t]{8}{*}{ Cargo release } & Disulfide bonds & $60,138,139,147$ \\
\hline & & Acid labile linkers & 61,150 \\
\hline & & Hydrazones & $97-99,155$ \\
\hline & & pH-triggered disassembly & $133,135-137,191$ \\
\hline & & Hyaluronidase mediated & 140 \\
\hline & & ATP-triggered disassembly & $141-143$ \\
\hline & & Self-degrading polymers & 144 \\
\hline & & Fluorination of polymers and dendrimers & $145-147$ \\
\hline & \multirow[t]{2}{*}{ Nuclear membrane } & Electroporation and deformation & 66 \\
\hline & & Incorporation of peptides with NLS sequences & 165,188 \\
\hline
\end{tabular}
carriers discussed in the text. 


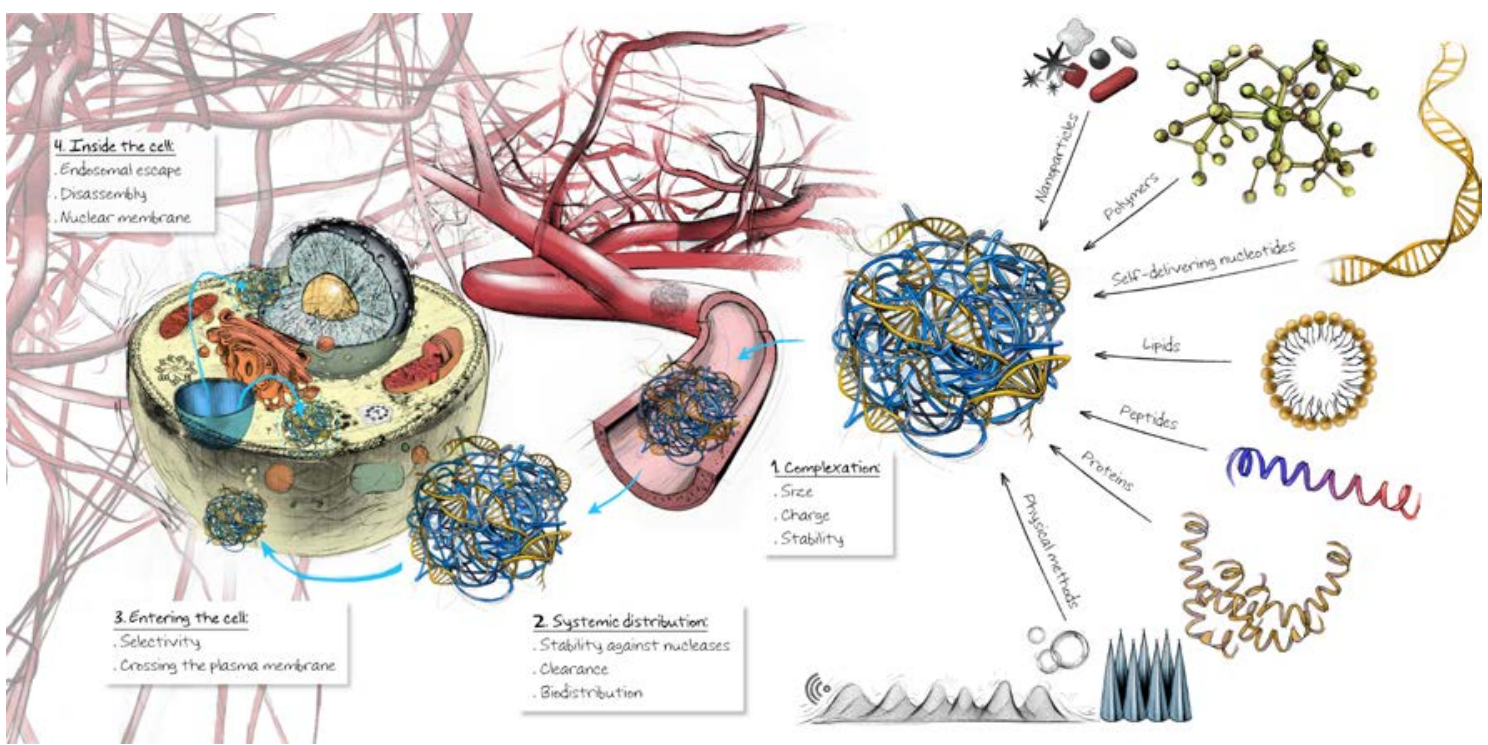

Figure 1. Different synthetic materials and current challenges for efficient intracellular gene delivery. The successful delivery of a functional nucleic acid requires overcoming important biological barriers. An initial condensation of the nucleotide cargo in particles of the right size and charge for delivery also contributes to the protection of the cargo against ubiquitous nucleases. The endothelial barrier, the hepatic and renal clearance, and the accumulation outside the target tissue might hinder the bioavailability of the therapeutic nucleotide in the in vivo systemic delivery. To reach its final intracellular destination, nucleotide vehicles have to cross the plasma membrane, escape from the endosome and cross the nuclear membrane, if necessary, for their activity.

\section{Non-viral delivery methods}

\subsection{Artificial "self-delivering" oligonucleotides}

Nucleotide chemical modifications. The activity and specificity of bioactive oligonucleotides depends mostly on their base sequence, while the biopolymer backbone usually plays a structural role. Therefore, nucleotides can tolerate the introduction of certain modifications on their structure that can improve their stability and uptake efficiency without affecting the recognition of its target. The chemical structure of oligonucleotide-based drugs has been in a state of permanent evolution to optimize their delivery and clinical applications ${ }^{32}$. Synthetically modified antisense oligonucleotides (ASOs) include, among others, phosphorothioate nucleotides (PS) in combination with locked nucleic acids (LNAs) ${ }^{39}$, tricyclo-DNA oligomers (tcDNA) ${ }^{40}, 2^{\prime}$-O-(2-Methoxyethyl)-oligonucleotides (2'-O$\mathrm{MOE})^{41}$ or 2'-deoxy-2'-fluoroarabinonucleotides (2'-F-ANA) ${ }^{42}$ (FIG. 2a). The substitution of the oxygen for a sulphur atom in phosphorothioate-modified antisense oligonucleotides (PS-ASOs) strongly reduces their nucleolytic degradation. The spontaneous uptake, or gymnosis, of these stabilized single stranded nucleotides has been observed both in vitro and in vivo ${ }^{39}$ and a number of formulations of phosphorothioate oligonucleotides have been approved for human use ${ }^{35}$, such as Fomivirsen for the treatment of cytomegalovirus retinitis ${ }^{43}$, or Mipomersen for homozygous familial hypercholesterolemia ${ }^{41}$. The inclusion of additional hydrophobic carbon atoms, between the C5' and C3' positions of the nucleotide of a phosphorothioate tricyclo-DNA (tcDNA), triggered its self-assembly into nanoparticles with a suitable size $(40-100 \mathrm{~nm})$ for in vivo delivery, and therapeutic improvement on a mouse model of Duchenne's muscular dystrophy ${ }^{40}$. However, nucleotide chemical modifications can sometimes give rise to adverse effects such as complement activation, trombocytopenia, increased off-target interactions, or intrinsic toxicity of the corresponding metabolites ${ }^{44}$. Particularly, modifications that increase nucleotide hydrophobicity at the 2 ' position such as in 2'-fluoro-modified phosphorothioate- $\mathrm{ASOs}^{45}$ and phosphorothioate-LNAs ${ }^{46}$ have been shown to be hepatotoxic in mice. Intriguingly, less hydrophobic modifications like in 2'-O-MOE (2'-O-(2-methoxyethyl)) or in constrained 2'-O-ethyl nucleotides did not show the same effect ${ }^{45}$. However, there is growing evidence that this toxicity, probably due to an increased affinity of these nucleotides towards the hepatic proteins, can be controlled by sequence design optimization ${ }^{46}$.

Charge reduction. The highly negatively charged phosphate backbone of nucleic acids blocks their interaction with the anionic components of the membrane and hinders its crossing of the non-polar membrane ${ }^{47}$, a situation that prevents the uptake of therapeutic oligonucleotides. The phosphate charges can be reduced by esterification and phosphotriester formation. The modification of the nucleotide phosphate, with the S-acyl-2-thioethyl (SATE) moiety, 
was optimized for 2' modified nucleotides (2'-F or 2'-O-Me) by employing the mild basic-sensitive phenoxyacetyl protecting group, which avoids phosphotriester hydrolysis at the nucleobase deprotection step. Although it cannot be applied to the whole sequence due to duplex destabilization, this esterification strongly increased the nucleotide bioavailability by binding to serum albumin. Additionally, fusion to cell penetrating peptides (CPPs) or glycan moieties (i.e. tris- $N$-acetylgalactosamine) enhanced the cellular uptake of the resulting hybrid oligonucleotides ${ }^{48}$. This elegant strategy allowed the high yield production of neutral siRNA derivatives (siRNN), in which the artificial thioester can be de-caged by cytosolic thioesterases to regenerate the original fully functional siRNA inside cells ${ }^{48}$ (FIG. 2b).

Programmable hybridization. The predictable and programmable folding of nucleotides can be employed to control the presentation of functional nucleotides and cell targeting sequences. This concept has been applied in gene targeted delivery by generation of active oligonucleotide/targeting aptamer chimeras such as aptamer-siRNA or aptamermiRNA chimeras ${ }^{49}$ (FIG. 2c). Analogously, a Y-shaped RNA scaffold containing anti miR-21 was combined with an EGFR aptamer, and the resulting chimera showed promising activity against breast cancer ${ }^{50}$. The programmable sequential recognition of a nanovehicle by two aptamers that are bound to two different cell receptors was employed for targeted gene delivery. The interaction of the nanovehicle with the first aptamer, bound to a cell surface receptor, cleaves a DNA loop by reconstitution of a MNAzyme. After this cleavage, a hybridization sequence of the nanovehicle is exposed and presented to the second aptamer that is bound to a different cell receptor. Hybridization with this second aptamer anchors the DNA nanovehicle to the membrane and enables specific endocytic internalization only in the cells where both receptors are present ${ }^{51}$. In addition to aptamers, fusion to other ligands can also be applied to trigger specific receptor-mediated endocytosis. The conjugation of antisense oligonucleotides or siRNA to tri-antennary- $N$-acetyl galactosamine is a widely used strategy for the targeted delivery to the hepatic asialoglycoprotein receptor (ASGPR) $)^{52-54}$ (FIG. 2c). The attachment of this particular glycan has also been confirmed to reduce the toxicity of the oligonucleotide conjugates ${ }^{55}$. PEG brushes have been also connected to antisense DNA (pacDNA) to increase the stability of the bioactive nucleotide against nucleases and facilitate its cellular uptake by endocytosis $^{56,57}$ (FIG. 2d). Larger single stranded DNA or RNAs, generated by rolling circle amplification or transcription techniques ${ }^{58,59}$, can fold into globular structures or "nanoflowers" (FIG. 2d). These nanoassemblies can include aptamer sequences for tumour targeting and DNAzymes to silence specific genes required for cell survival ${ }^{58}$. Similar stimuli-responsive RNA nanoparticles have been recently developed to release multiples copies of siRNA inside the cell ${ }^{59}$. These cleavable RNA nanoparticles consist of a long ssRNA containing repetitions of a siRNA antisense strand hybridized with chimeric DNA-RNA sense strands. These DNA/RNA duplexes were coated with a glutathione sensitive chitosan polymer for delivery and they were cleaved inside the cell by the cellular $\mathrm{RNaseH}^{59}$.

Dynamic covalent linkers. Attaching large structures to a nucleotide cargo may impair its biological activity. Covalent dynamic linkers (i.e. disulfide) can be used to connect the nucleic acid and the non-viral vehicle. These dynamic linkers can be cleaved by external stimuli (i.e. proteases, $\mathrm{pH}$ changes, reducing agents) and thus release the intact nucleic acid material at the suitable tissue or intracellular location. A multifunctional cationic amphipathic polymer can be grafted, via $\mathrm{pH}$ or protease sensitive linkages, to PEG and $N$-acetylgalactosamine pendants and connected to a siRNA cargo by a disulfide bond ${ }^{60}$. In the first step, the protease or $\mathrm{pH}$-mediated cleavage restored ligand targeting and membrane interaction and, once inside the cell, the cleavage of the disulfide bonds triggered cargo release ${ }^{60}$. In a different conceptual strategy, nucleic acids that are recognised by a polypeptide sequence can function as simple carriers for the delivery of transcription factors for gene expression regulation. In DNA assembled recombinant transcription factors (DARTs), the nucleic acid acts as a simple carrier and it can be decorated with glycan residues via a dynamic acetal linker that after hydrolysis unmasked hydrophobic endosomal disrupting domains to facilitate cargo delivery (FIG. 2e) ${ }^{61}$. 


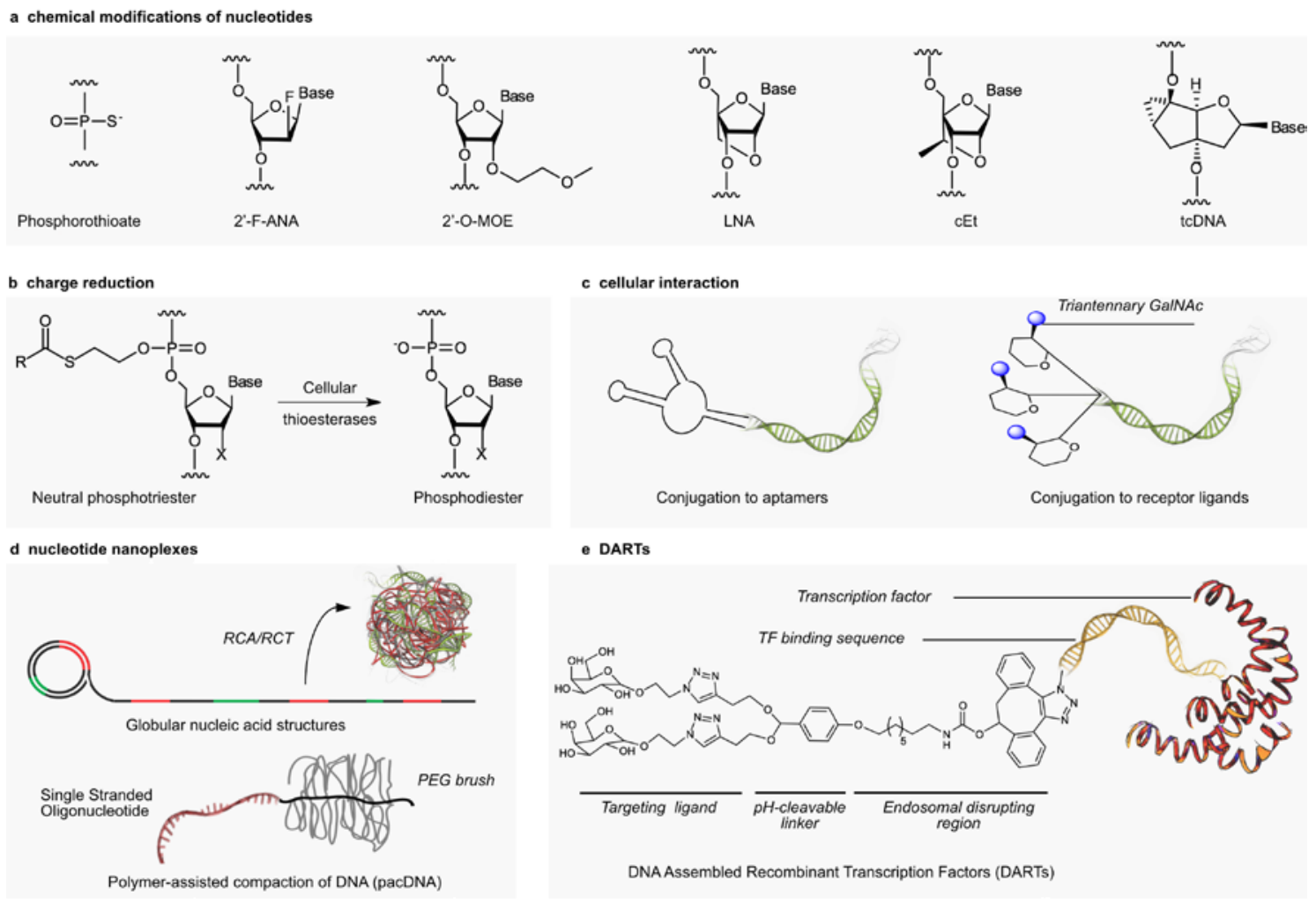

Figure 2. Modifications for self-delivering oligonucleotides. a) Chemical modifications of nucleotides for gymnotic delivery. These modifications usually involve a phosphorothioate backbone (left) combined with additional modifications of the ribose, such as those pictured here. b) Phosphotriester modification reduces the negative charge of the oligonucleotide and can be reversed by the activity of cellular thioesterases, to get the natural phosphodiester. c) Examples of delivery systems that exploit cellular interaction for uptake, such as receptor-binding aptamers or glycan moieties attached to siRNA. d) Formation of globular structures, by the folding of long ssDNA or ssRNA strands obtained by rolling circle amplification or transcription (RCA or RCT) that can contain aptamer sequences or multiple repetitions of the active sequence, or by attachment of polymeric brushes that turn antisense oligonucleotides into compact particles. e) An example of the $\mathrm{pH}$-sensitive dynamic linkers found in DARTs.

\subsection{Delivery assisted by physical methods}

The efficiency and low cost of physical gene transfection has recently triggered a rebirth of this field. Although with certain limitations for in vivo applications, excluding cutaneous treatment ${ }^{62}$ or local hydrodynamic gene delivery to liver or muscle ${ }^{63}$, physical methods can be very useful for ex vivo gene therapy. In ex vivo therapies, patient cells are removed, modified (i.e. transfected) under in vitro conditions and then reinfused into the patient. Electroporation, osmotic shocks or microinjection allow direct delivery of the oligonucleotide to the cytoplasm or nucleus, circumventing any endosomal pathway and/or nuclear membrane barrier ${ }^{64}$, because of the transient extensive disruption of the plasma and nuclear membranes. However, this aggressive technique can lead to severe cellular damage and new technologies are being developed to allow a better control of the degree of membrane disruption ${ }^{64}$. Indeed, physical gene delivery is currently in the pipeline for therapeutic applications such as cancer immunotherapy by chimeric antigen receptors (CAR), in where the T-cells of a patient can be extracted, physically transfected ex vivo and the new reprogrammed T-cells re-injected into the same patient to seek and destroy the tumour ${ }^{65}$. Recently, the combination of electroporation and microfluidic cell deformation has been explored for high throughput plasmid, mRNA or protein delivery ${ }^{66}$. The application of nanoneedles in drug and gene delivery is generally associated with inflammation ${ }^{62}$ which can be useful for vaccination but undesirable for other purposes. Biodegradable porous silicon nanoneedles have recently been developed, which increases their in vivo tolerance and safety ${ }^{67}$, and extends their potential applications. The collapse of gas-filled microbubbles, under target-directed ultrasound, was applied in systemic delivery of drugs ${ }^{68}$. However, the stabilization of microbubbles for DNA delivery usually requires microbubble functionalization with binary lipid mixtures to avoid perturbation of their acoustic properties ${ }^{68}$. A recent screening of these stabilizing lipids identified a single dimyristoyl cationic lipid branched with polyspermine and partially decorated with PEG. This single lipid formulation was able to deliver a miniplasmid to hepatocytes achieving long term gene expression ${ }^{69}$. Microbubbles can also be used for the targeted delivery of promiscuous cationic liposomes ${ }^{70}$. These plasmid loaded cationic liposomes can be functionalized with PEG and heparin to inhibit 
off-target uptake. The precise ultrasonic disruption of co-injected microbubbles triggered the local release of the liposomal contents ${ }^{70}$. Acoustic transfection, directly based on membrane disruption due to cavitation, can also achieve in vitro plasmid, mRNA or protein transfection with single cell resolution ${ }^{71}$.

\subsection{Carrier mediated}

\subsubsection{Protein based}

Virus-like particles. Protein vehicles can also be employed to protect and deliver bioactive nucleotides. The encapsulation of nucleotidic cargo into a protein container is a ubiquitous strategy in nature in viruses and in higher organisms $^{72}$. For instance, the Arc protein, evolutionary related to transposon's gag protein, forms enveloped viruslike particles that are able to deliver its own mRNA across neurons or the neuromuscular junction in mammals and insects $^{72}$. Virus like particles (VLPs) that are reconstructed from proteins of the natural virus can encapsulate active oligonucleotides, inhibiting tumour growth by intracellular delivery of a suicide gene ${ }^{73}$. Interestingly, the strong immunogenicity of VLPs can be reduced by particle surface modification with polymers such as polynorbornene or polyethylenglycol ${ }^{74}$. Decoration of VLPs with targeting moieties can redirect these artificial capsids to other tissues, as was demonstrated by the attachment of transferrin or aptamers to polyomavirus VLPs ${ }^{75}$ or phages ${ }^{76}$.

RNA binding proteins. dsRNA-binding domains are common in proteins of viral and non-viral origin and can be used for siRNA protection and delivery (FIG. 3a). A fusion protein composed of dsRNA-binding domains, from the protein kinase PKR, fused to a penetrating peptide sequence, was confirmed to deliver siRNA in hard-to-transfect cells and in vivo by intranasal inoculation ${ }^{77}$. To achieve an efficient intracellular siRNA delivery, the binding between the protein and the nucleotide has to be strong enough to protect the cargo, but it also has to be disrupted in the last step of the delivery process. A systematic study using high-affinity dsRNA binding proteins, derived from p19 of Carnation Italian Ringspot Virus, showed that, even for dissociation constants in the low pM range, the inhibitory binding-limit was not reached ${ }^{78}$. However, to achieve cytosolic delivery of the siRNA in this study a second pore forming Perfringolysin O protein was required to achieve endosomal escape ${ }^{78}$.

Bioavailability enhancers. Association with certain proteins can improve cargo pharmacokinetics, as the bigger protein/cargo complexes can circumvent renal clearance and extend their serum half-life by the exocytosis-recycling pathway. The non-covalent binding of lipid modified oligonucleotides to albumin has been applied to enhance the bioavailability of siRNA ${ }^{79,80}$ and other antisense oligonucleotides ${ }^{81}$. Conjugation of nucleotides to antibodies can also provide improved pharmacokinetics and targeting capacities. A fusion protein composed of HIV specific F105 antibody fragment and protamine, as a nucleic acid binding protein, was designed and confirmed to deliver a siRNA specifically to HIV infected cells ${ }^{82}$. After attachment of siRNA to antibodies, by redox sensitive disulfides in THIOMAB antibodies, no improvement in activity was found between a dynamic linker and a covalent connector. These results indicate that a reversible bond is not a prerequisite for activity ${ }^{83}$, as the linker is at the sense strand and it might not affect the antisense strand loading into the RISC complex. However, in all these examples of protein mediated delivery, the endosomal escape is usually the limiting factor and the addition of endosomolytic agents as pore forming toxins ${ }^{78}$ or $\mathrm{CPPs}^{77}$ is sometimes required to achieve efficient cargo delivery.

\subsubsection{Peptides}

Cell penetrating peptides (CPPs) have been extensively applied to the delivery of nucleic acids ${ }^{84,85}$, as covalent or non-covalent conjugates. Recent research on CPPs has focused on the development of new synthetic peptides for the delivery of artificial nucleotides (TABLE 3). Artificial PMO nucleotides have been conjugated to peptides of the Pip family $^{86}$ and arginine-rich peptides ${ }^{87}$ that include non-proteinogenic aminoacids such as 6 -aminohexanoic or $\beta$ alanine. The resulting conjugates achieved therapeutic levels of cargo delivery in different animal models of muscular dystrophies $^{86,87}$. The cationic amphiphilic CLIP6 cell penetrating peptide presents a D-proline at the middle of its sequence, together with a glutamic acid that disrupt its potential $\beta$-sheet secondary structure ${ }^{88}$. This "intrinsically disordered" peptide was able to reach the cell cytosol by a non-endocytic mechanism ${ }^{88}$ for PNA efficient delivery ${ }^{89}$. Amphiphilic peptide nanofibers, composed of a short cationic sequence and a $\beta$-sheet seed followed by a hydrophobic tail, can also be employed for slow release of antisense oligonucleotides in vitro ${ }^{90}$ and for localized siRNA delivery in vivo by stereotactic surgery ${ }^{91}$. Peptide nanofibrils ${ }^{92}$ or nanosheets ${ }^{93}$ can be implemented as enhancers of viral gene transfer ${ }^{92}$. These amyloids have the ability to concentrate and increase infectivity of lentiviruses, a very promising technology with multiple potential ex vivo applications ${ }^{92}$. In the RALA peptide, a variant of the amphiphilic GALA ${ }^{84}$, the protonation of glutamate residues prevents the anionic repulsion between peptide side chains and triggers helical folding. This secondary structure fluctuation allows membrane disruption at low $\mathrm{pH}$ and RALA mediated intracellular delivery of plasmids ${ }^{94}$ or mRNA $^{95}$. Artificial non-peptidic foldamers have also emerged as biocompatible vehicles for gene delivery. Disulfide connected dimers of amphiphilic oligourea helical foldamers, equipped with imidazole and isopropyl moieties, were recently shown to deliver plasmid DNA in 
cells with low toxicity ${ }^{96}$. Dynamic bonds such as oximes or hydrazones are formed in mild aqueous conditions, with good yields, short reaction times and in a fully bio-orthogonal fashion. Combinations of cationic hydrophilic peptides with hydrophobic tails of different lengths and properties have allowed the straightforward screening and quick identification of new simple formulations for siRNA ${ }^{97}$, plasmid ${ }^{98}$ or Cas9 delivery ${ }^{99}$. The recently introduced guanidiniocarbonylpyrrole group can form four hydrogen bonds with the phosphate of nucleotides ${ }^{100}$ (FIG. 3b) and thus enhance the plasmid delivery capabilities of short peptides ${ }^{101}$. Cyclic peptides of alternating chirality ${ }^{102}$ incorporating guanidiniocarbonylpyrrole can self-assemble into fibers that can also be applied in plasmid transfection $^{100}$. Alternation of guanidiniocarbonylpyrrole and cyclohexylalanine afforded large amyloid peptide fibers that can be further processed with gold nanoparticles to obtain nanoparticles of the right size for cell transfection ${ }^{103}$. Another recent and interesting approach is the use of peptides with biological activity as carriers ${ }^{104}$. For instance, the peptide PepM, derived from a Dengue virus protein, reduces by itself the number of mitotic cells and can also be used for siRNA delivery in combined therapy ${ }^{104}$.

\begin{tabular}{|lll|}
\hline Peptide & Sequence & Notes \\
\hline Pip6 $^{86}$ & RXRRBRRXRYFLIRXRBRXRB & $\mathrm{X}=$ aminohexanoic acid, B = $\beta$-alanine \\
\hline Peptide B $^{87}$ & RXRRBRRXRRBRXB & $\mathrm{X}=$ aminohexanoic acid, B $=\beta$-alanine \\
\hline CLIP6 $^{88,89}$ & KVRVRVRVpPTRVRERVK & $\begin{array}{l}\text { p = D-Proline } \\
\text { Cross directly the cell membrane. }\end{array}$ \\
\hline Lys-PA $^{90}$ & Lauryl-VVAGK & Nanofibers forming peptide. \\
\hline PNF $^{91}$ & Palmitoyl-GGGAAAKRK & Nanofibers forming peptide \\
\hline EF-C $^{+2} 92$ & QCKIKQIINMWQ & $\begin{array}{l}\text { Derived from HIV gp120. Enhances retroviral } \\
\text { infection. }\end{array}$ \\
\hline $\begin{array}{l}\text { Amyloid- } \\
\text { forming } \\
\text { heptapeptide }\end{array}$ & KLVFFAK & $\begin{array}{l}\text { Derived from the Italian familial form of Alzheimer's } \\
\text { A } \beta\end{array}$ \\
\hline RALA $^{94,95}$ & WEARLARALARALARHLARALARALRACEA & Enhances retroviral infection \\
\hline PepM $^{104}$ & KLFMALVAFLRFLTIPPTAGILKRWGTI from GALA peptide. & $\begin{array}{l}\text { Residues 45-72 of Dengue virus 2C protein. } \\
\text { Perturbs Bcr-Abl1 signalling. }\end{array}$ \\
\hline
\end{tabular}

Table 3. Selected examples of peptide sequences for gene delivery.

\subsubsection{Lipid based}

Enhancing membrane fusion. Lipofection has been one of the most popular methods of transfection since the discovery that cationic lipids spontaneously condense DNA and fuse with cell membranes ${ }^{105}$. Current efforts in this field are focused on enhancing the fusogenic properties of the liposomes and minimizing their toxicity. In most cases, membrane fusion of liposomes is optimized to overcome the endosomal entrapment, while direct fusion with plasma membrane and subsequent direct delivery in the cytosol has received much less attention ${ }^{106}$. Inspired by SNARE proteins responsible for vesicle fusion in cells, artificial liposomes exposing one of the peptides of a coiled-coil motif specifically delivered siRNA and splice correcting oligonucleotides in cells that were previously loaded with the corresponding coil counterpart peptide ${ }^{107}$ (FIG. 3c). The application of this methodology has allowed the preparation of different fusogenic peptide liposomes for the direct intracellular release of vesicular contents ${ }^{108}$. Cell surface engineering by ketone-containing lipids has been recently applied to cell transfection with the corresponding lipoplex containing bio-orthogonal reactive alkoxyamine functionalities ${ }^{109}$ (FIG. 3d). However, the in vivo application of these creative approaches will require the challenging selective ketone-lipid or coil modification of the target cells ${ }^{107,109}$. The lipid transfection helper DOPE bears two bulky oleyl hydrophobic tails giving rise to a conical shape lipid that tends to assemble into the less stable hexagonal phase instead of the lamellar phase adopted by other lipids with higher head to tail surface ratio ${ }^{110,111}$. The Safinya group recently demonstrated that inverse bicontinuous gyroid cubic nanostructures, confirmed by X-ray scattering, could also enhance fusion with the endosome membrane and efficiently deliver siRNA without the requirement of a high cationic charge ${ }^{112}$ (FIG. 3e). Although these cuboplexes were not able to transport longer DNAs, they can be further modified with PEG for additional stabilization without activity loss, pointing towards future in vivo applications ${ }^{113}$.

Lipid nanoparticles engineering. Lipid nanoparticles can be modified by using mixtures of different lipids in which not only the lipid composition, but also the synthesis method, can have a great impact on the size, the biodistribution and the delivery efficiency ${ }^{114}$. Typically, they contain a pegylated lipid, cholesterol, a helper lipid and an ionizable lipid. The cross-reaction of alkylamines with alkylacrylates with different hydrophobic tails generated a library of ionizable lipidoids that were combined with cholesterol, DSPC and PEG-DMG to formulate nanoparticles for siRNA delivery. This strategy allowed the extraction of structural insights about ionizable lipid nanoparticles for endosomal escape and for in vivo delivery. The most effective formulations included lipidoids with three or more hydrophobic tails, secondary and tertiary amines and a particle surface $\mathrm{pK}_{\mathrm{a}}$ of around 5.5-7115. Recent studies on ionizable lipids 
also stressed the importance of tertiary amines and the steric constraints for the conformational switch of the lipids that triggers endosomal escape by changing the relative orientation of the hydrocarbon chains ${ }^{116}$ (FIG. 3f). The net surface charge of liposomes can alter their biodistribution, as shown by DOTMA and DOPE mixed liposomes that accumulated in the lung when having a positive charge or in the spleen as the negative charges increased. This property was exploited to deliver mRNA to dendritic cells for the development of mRNA vaccines against cancer ${ }^{117}$. In a similar strategy, lipid nanoparticles containing phospholipids, ionizable and PEG-modified lipids, cholesterol, and a lipopolysaccharide adjuvant, were loaded with mRNA and the subcutaneous injection of these liposomes triggered an immune response that could overcome the critical self-tolerance against auto-antigens required in cancer immunotherapy ${ }^{118}$. Thiol-conjugated lipids/aptamers can be also assembled into nanoparticles and employed in targeted delivery of siRNA to different tissues such as bone to improve osteogenesis ${ }^{119}$. Polydiacetylenic derivatives with protonable amine or imidazol groups can be crosslinked with UV light to generate interesting structures, such as nanomicelles ${ }^{120,121}$ or nanofibers ${ }^{122}$ that are suitable for plasmid and siRNA delivery. The clinical potential of lipid engineering is exemplified by Patisiran, a siRNA drug against hereditary transthyretin-mediated amyloidosis, which is delivered by lipid nanoparticles containing DLin-MC3-DMA ${ }^{38,123}$.

Exosomes and Sterosomes. Exosomes are naturally produced vesicles containing lipids, proteins and nucleic acids that can act as natural carriers of proteins and nucleic acids. Generally, extravesicular engineering has been carried out by the loading of exogenous agents and by the genetic engineering of parental cells ${ }^{124}$. However, until recently the chemical modification of exosomes for gene delivery has been surprisingly overlooked. In an interesting biotechnological strategy, fusogenic liposomes were used to load the membrane of living cells with azide modified artificial lipids. The chemically modified exosomes produced by these cells can then be easily further functionalized by click chemistry, for example by conjugation with targeting peptides ${ }^{125}$. In recent examples, the loading of exosomes with synthetic oligonucleotides was simplified by the use of hydrophobic cholesterol-modified siRNA $^{126,127}$. Despite their promising properties, the cellular origin of exosomes constitutes an important challenge in terms of their large-scale production with standard sizes and compositions. Sterosomes, cationic liposomes enriched in steroles and stearylamine, can provide a more stable alternative to phospholipid liposomes, as they are less affected by hydrolysis and oxidation ${ }^{128}$ (FIG. 3g). Sterosomes have been embedded in hydrogels for sustained noggin siRNA delivery to enhance osteogenic differentiation during bone regeneration ${ }^{128}$. 


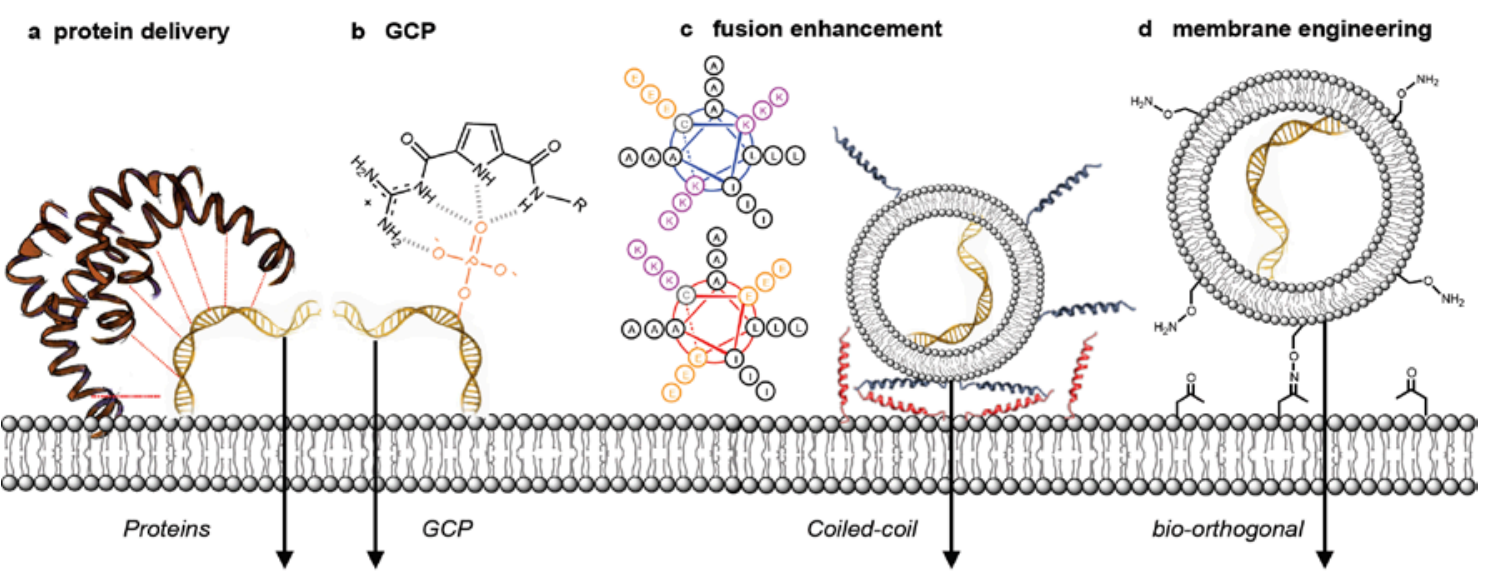

e gyroid cubic phases

f ionizable lipids and lipidoids

g sterosomes
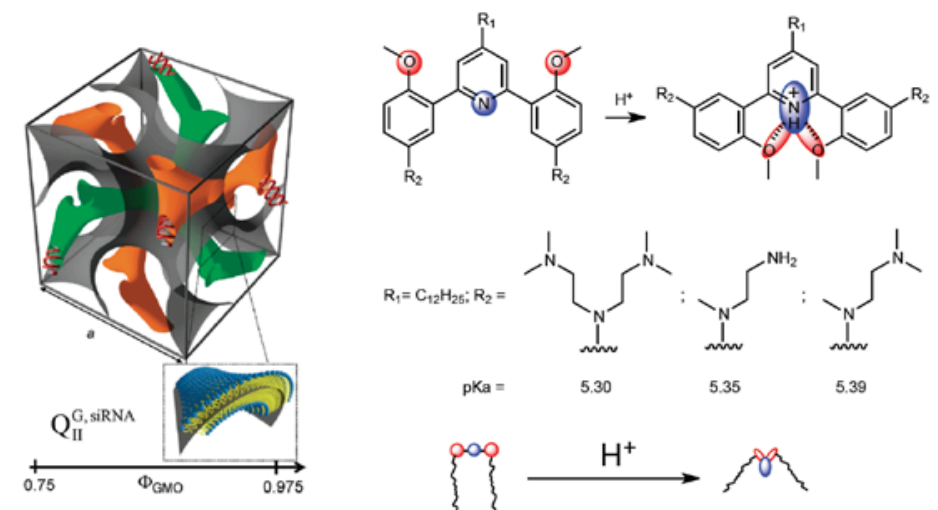

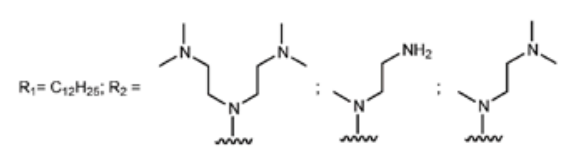
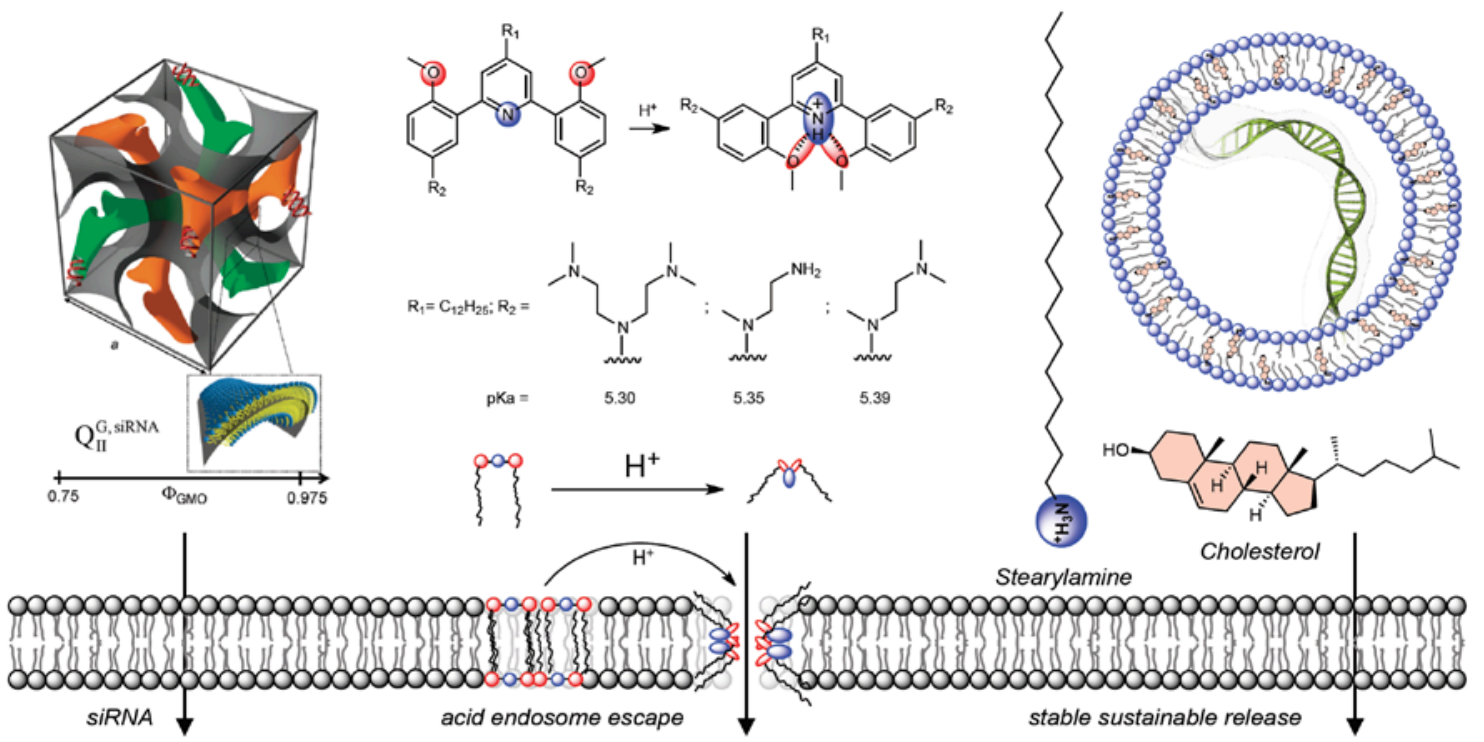

Figure 3. Peptide and lipid based delivery systems. a) dsRNA binding proteins can be used for the recognition and delivery of siRNA. b) Guanidiniocarbonylpyrrole (GPC), showing the four potential hydrogen bonds that can be established with the phosphate backbone. c) Mechanism of fusion enhancement between cellular membranes and liposomes, by exploiting the formation of coiled-coils of peptides present in the liposome carrier and the cell membrane target. According to the cartoon, the helical wheel representation of the coil of the vesicle (in blue) and the coil of the cell membrane (in red) include the following amino acids: hydrophobic (A, L, I in black), cationic (K in purple) and anionic ( $\mathrm{E}$ in orange). d) Bio-orthogonal reaction between the alkoxyamine bearing lipids of the liposome vehicle and a cell membrane loaded with lipids exposing ketone groups. e) Structure of cuboplexes, whose topology allows membrane fusion without the requirement of a high cationic charge (reproduced with permission from REF. 112; Copyright $\odot$ 2010, American Chemical Society). f) Ionizable lipids contain a head with protonable groups and flexible bonds that allow conformational changes when the head is protonated. The conformational change induced by protonation in the lipid library synthesized by Viricel et al. is depicted. g) Sterosomes are alternatives to phospholipid liposomes prepared by mixing stearylamine with esteroles such as cholesterol and its derivatives.

\subsubsection{Polymers, dendrimers and micelles}

pH disassembly. Polymers can display, in a multivalent fashion, the functionalities that are required for membrane recognition, interaction and translocation. This structural versatility and the potential synthetic scalability turn synthetic polymers into one of the most promising artificial materials for gene delivery. The current research efforts in polymeric materials for gene delivery are focused on improving condensation of the cargo, the reduction of the toxicity and the enhancement of the endosomal escape. To achieve these challenging goals, new polymers have been designed to disassemble upon the exposure to external stimuli such as reducing agents, enzymes, light, temperature, and above all, $\mathrm{pH}$. The cooperative $\mathrm{pH}$ triggered disassembly of poly(2-(diisopropylamino) ethylmethacrylate) (PDPA) offers an excellent conceptual advance for micelle disruption and cargo release at the tumour microenviroment ${ }^{129}$ (FIG. 4a). This concept was exploited in PDPA ultrasensitive pH co-polymers containing RGD 
peptide, PEG, and grafted with cationic lipid-like structures ${ }^{130,131}$. The resulting grafted nanoparticles showed a very targeted delivery ${ }^{130,131}$. In an analogous approach, the $\mathrm{pK}_{\mathrm{a}}$ of low uptake cationic micelles was tuned by adjusting the ratios of its components (PDPA and PDMAEMA). At the optimal $\mathrm{pK}_{\mathrm{a}}$ (6.8-7), an excellent siRNA delivery was observed even at low cellular uptake or in hard-to-transfect cells ${ }^{132}$. The $\mathrm{pH}$-dependent aggregation of oligoethyleneimines (OEI) was optimized by the attachment of different aromatic pendants, such as salicylate (SaOEI), to maximize the $\mathrm{pH}$-triggered disassembly and cargo release of polyplexes with different nucleic acids ${ }^{133}$ (FIG. 4a). The pH-triggered dissociation of polyplexes can also be used to release a hidden membrane-lytic peptide to enhance nucleotide release ${ }^{134}$. This method avoided the membrane disruption until the complex reached the endosome and thus reduced the toxicity of the final formulation ${ }^{134}$. A different $\mathrm{pH}$-triggered strategy to change polymer properties, from hydrophobic to hydrophilic, to trigger polyplex disassembly and plasmid delivery, explored the $\mathrm{pH}$ dependent cleavage of benzoic aromatic imines to generate cationic amines ${ }^{135}$. Charge altering releasable transporters (CARTs) are composed of oligo(carbonate- $b$-alpha-amino ester) and a lipophilic block. CARTs polymers lose their charge and self-immolate at cytosolic $\mathrm{pH}$, by intramolecular amide formation and piperazines release, to efficiently deliver mRNA both in vitro and in vivo ${ }^{136}$ (FIG. 4a). Self-replicating alphavirus replicons are large RNA molecules that can sustain prolonged protein expression but they do not tolerate structural chemical modifications. To protect them from nucleases, these replicons can be formulated with cationic ionizable dendrimeric poly(amido amine) and pegylated lipids before intramuscular injection for their in vivo use as RNA vaccines ${ }^{137}$.

Redox, enzymes and other strategies for polyplex disassembly. Several other strategies have been studied to trigger nucleotide release from polymeric formulations. The disulfide bond can also be exploited in polymers that disassemble in the reducing cytosolic environment. The transfection efficiency of branched PEI was enhanced by polymer disulfide functionalization with zinc dipicolylamine analogues, which increases vehicle DNA affinity, membrane binding and transfection efficiency ${ }^{138}$ (FIG. 4b). Pegylated polymers, carrying dithiolane rings for disulfide crosslinking, can be assembled into nanoparticles loaded with siRNA (FIG. 4b). These nanoparticles were decorated with tumour targeting peptides and showed virus-like cell attachment and "capsid uncoating” behaviour in the cytosol ${ }^{139}$. In a different enzymatic disassembly strategy, a core-shell artificial virus was prepared by covering a fluorinated cationic polymer and a DNA core with an outer shell made of a polymer of hyaluronan with PEG and R8RGD peptides. The degradation of this layered polyplex was mediated by the hyaluronidase overexpressed in the tumour environment, which exposed the particle core and allowed the in vivo delivery of problematic large plasmids ${ }^{140}$. Polyols, including siRNA, can be stabilized by reversible ester formation of the 2-cis-diols of the terminal ribose or other polymers with phenylboronate ${ }^{141}$. After uptake, these boronate-stabilized particles can be disrupted by the high levels of internal ATP triggering siRNA ${ }^{142}$ or plasmid release ${ }^{143}$ (FIG. 4b). In other cases, instead of a stimulus, timed degradation can be used to protect the cargo until cytosolic delivery. This is true in the case of poly(2-dimethylaminoethyl acrylate) (PDMAEA), a cationic polymer that slowly self-degrades into a negatively charged compound that repels its cargo for siRNA release ${ }^{144}$ (FIG. 4b).

Fluorinated dendrimers and polymers. PAMAM perfluorinated dendrimers condensate plasmid DNA at very low N/P ratios, reducing its positive charge and thus lowering toxicity and increasing efficiency in the presence of serum $^{145,146}$. Their hydrophobic and lipophobic properties reduce their membrane interactions and increase their ability to penetrate tissues and spheroids ${ }^{146}$. This intriguing principle was applied in bioreducible PEI micelles with a perfluorinated core that showed good activity in DNA delivery ${ }^{147}$. Polymer fluorination has also shown excellent potential for the delivery large plasmids ${ }^{140}$ and proteins ${ }^{148}$.

Supramolecular chemistry and dynamic chemistry. Weak non-covalent bonds like electrostatic and hydrophobic interactions control the dynamic processes of nucleotide complexation, protection, membrane translocation and complex disassembly. Therefore, supramolecular chemistry and supramolecular templates are powerful tools to understand and to develop conceptually new non-viral vectors. Cyclodextrin-based carriers consist of a linear cationic polymer containing cyclodextrins that can complex with siRNA and then incorporate targeting and stabilizing moieties by supramolecular host-guest chemistry with adamantane conjugates ${ }^{36,149}$. This modular strategy originally developed by Mark Davis ${ }^{149}$ has been recently modified by using non-polymeric cyclodextrin with LMW PEI pendants that are stabilized with $\mathrm{pH}$ sensitive polyketal poly-adamantanes ${ }^{150}$ (FIG. 4c). Cyclodextrins polymers have also been recently used in tumour targeted combined therapy with a chemotherapeutic agent and plasmid DNA ${ }^{151}$. Amphiphilic polymers with a hydrophobic core, capped with dendronized dipeptides, enriched in aromatic tryptophan or $\mathrm{pH}$ responsive histidine residues, performed as good in vitro delivery vectors for siRNA ${ }^{152}$. However, cyclodextrins have recently showed toxicity problems in phase one clinical trials ${ }^{37}$. The use of thiol click-chemistry allows the fast preparation of libraries of polyesters for siRNA delivery that can show selectivity to tumour cells ${ }^{153,154}$. Hydrazone-modulated polymers have also been recently introduced as a promising alternative to screen for polymer nucleotide vehicles. In this strategy, poly-hydrazides can be modified with different combinations of 
cationic and hydrophobic aldehydes to generate a library of amphiphilic polymers that can complex and deliver siRNA and plasmid in living cells ${ }^{155,156}$ (FIG. 4d).

Combined therapies. In several recent examples, the polymer can also play an active role and contribute to an additional therapeutic function instead of acting as a mere carrier. PolyMetformin, derived from the anticancer and antidiabetic drug metformin (dimethyl biguanide), has the ability to complex siRNA while preserving its anticancer properties and it can be formulated with lipids and co-delivered into tumour cells ${ }^{157}$ (FIG. 4e). A dendronized dithiophene semiconducting polymer can also deliver a plasmid and trigger the expression of genes regulated by heat shock proteins by near infrared photothermal activation ${ }^{158}$.

Glycan, protein and antibody conjugates. $N$-acetyl-D-galactosamine pendants have been incorporated in guanidinium polymers to enhance targeting and reduce toxicity in the transfection of HepG2 cells ${ }^{159}$. Similar behaviour has been observed in poly(glycoamidoamines) and PEI derived polymers that incorporate carbohydrate (D -glucaric acid) co-monomers ${ }^{160}$. These materials have been further modified by adding alkyl chains to obtain polymer brush materials loaded with siRNA, mRNA and lipids to produce nanoparticles with in vivo activity ${ }^{161}$. The introduction of alkyl chains to enable self-assembly with other hydrophobic compounds, such as pegylated lipids, has been applied to poly( $\beta$-amino esters) (PBAE), to generate nanoparticles to deliver mRNA to the lungs ${ }^{162}$. Another problem with mRNA delivery is that certain cationic carriers can mask the m7G cap at the 5' end, blocking its recognition by cellular proteins and inhibiting mRNA translation. To improve translation initiation, mRNA can be pre-assembled with eIF4E, the protein involved in cap recognition, a technique that enhanced mRNA expression, both in vivo and in vitro ${ }^{163}$. Programmable self-assembly was exploited to prepare dendrimeric siRNAs that were efficiently complexed to PBAE polymers or branched and linear PEI ${ }^{164}$. PBAE polymers containing peptides with microtubule-associated sequences and nuclear localization signals were employed to overcome the limitation of crossing the nuclear membrane for plasmid delivery in non-dividing cells ${ }^{165}$. In a recent and extraordinarily promising approach, a plasmid DNA packed with this PBAE polymer was coated with poly(glutamic) acid fused to a targeting antibody and the resulting polyplex allowed in vivo reprogramming of T-cells with CARs for the treatment of a leukemia model ${ }^{165}$. 


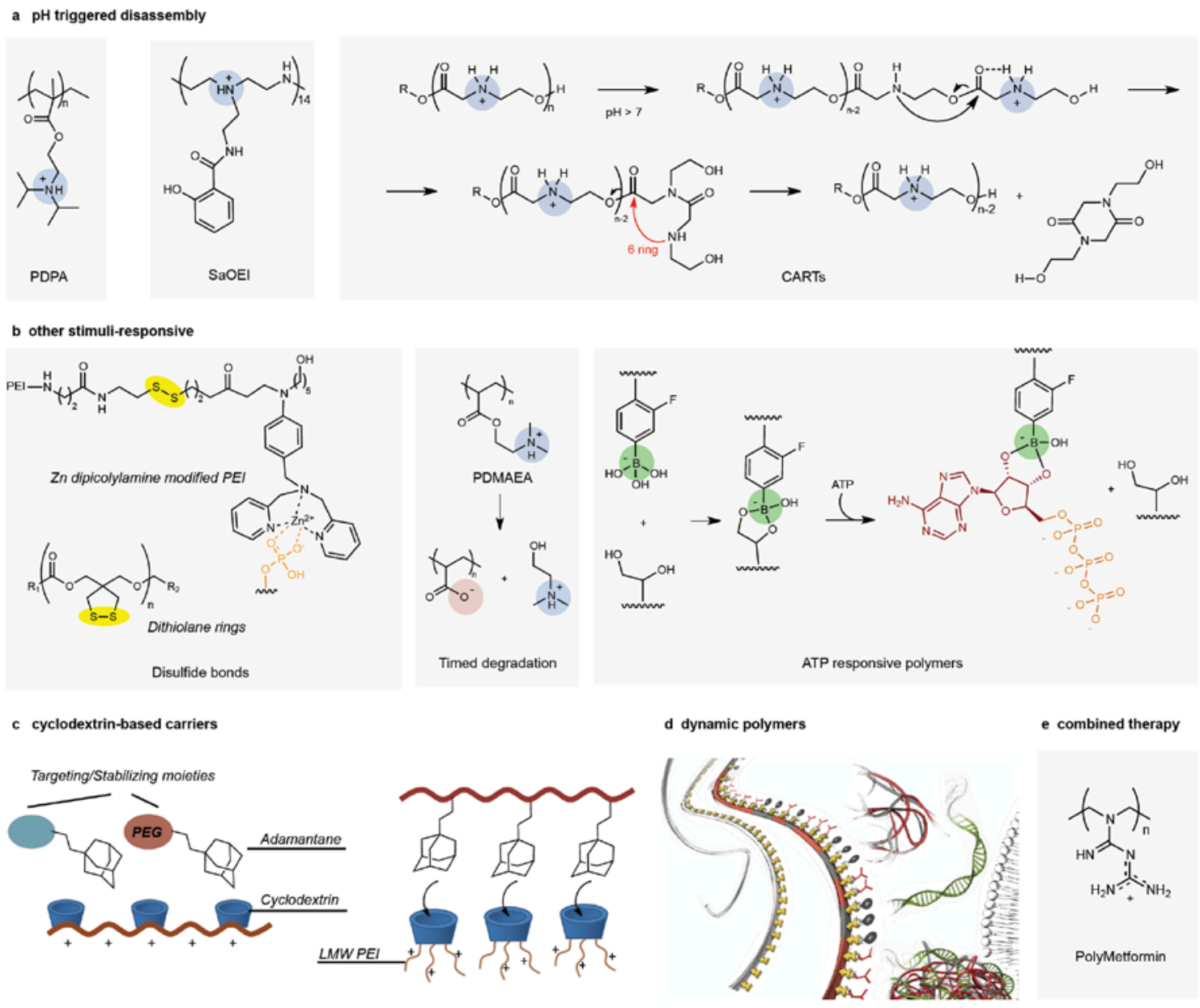

Figure 4. Polymeric approaches to gene delivery. a) Structures of $\mathrm{pH}$-sensitive polymers. PDPA gets protonated at low $\mathrm{pH}$ and electrostatic repulsion disassembles the polymeric structure. Salicylic acid modification of oligoethyleneimine (SaOEI) reduces its affinity for nucleic acids at low $\mathrm{pH}$ and contributes to the disassembly of the polyplexes. CARTs are self-immolative polymers that degrade at $\mathrm{pH}$ higher than 7. b) Polymers that respond to other stimuli. Disulfide bonds can be used for disassembly in the reducing conditions of the cytosol, as in the case of zincdipicolylamine modified PEI or dithiolane rings that can be introduced in the polymer sequence for crosslinking and stabilization of the nanoparticles. Cationic PDMAEA spontaneously degrades into the negatively charged poly(acrylic acid). ATP responsive polymers are based on the reversible interaction of phenylboronic acid with diols. c) Cyclodextrins can be incorporated into cationic polymers (left) and then modified with different compounds (PEG, targeting moieties...) using adamantane or another hydrophobic residue that interact with the cyclodextrin. Alternatively, individual cyclodextrins can be decorated with shorter cationic polymers for nucleic acid interaction and then assembled into larger structures using poly-adamantanes (right). d) Conceptual scheme for dynamic polyhydrazones. Dynamic hydrazide polymers can be combined with different aldehydes to afford cationic amphiphilic polyhydrazone for nucleotide delivery. (Reproduced with permission from REF. 155). e) Example of a polymeric nucleotide vehicle, polyMetformin, that presents intrinsic biological activity for combined therapy.

\subsubsection{Nanoparticles}

Carbon allotropes. The use of inorganic structures for plasmid delivery can be loosely tracked back to the 70 s, with the development of the calcium phosphate co-precipitation method for DNA delivery into cells ${ }^{166}$. Since then, the nanoparticle field has evolved tremendously with substantial improvements being made in the characterization of nano-structures and the implementation of novel functionalities. Carbon nanoforms constitute promising materials for a range of diagnostic tools and biomedical therapies ${ }^{167}$. The potential toxicity of carbon nanostructures can be modulated by controlling the size and by modifying the surface of the nanoparticles, and thus chemistry plays a key role in turning carbon allotropes into biocompatible scaffolds ${ }^{167}$. In gene delivery, chemically functionalized carbon nanotubes (CNs) exploit their high aspect ratio to rupture or to slip through the lipid bilayer (FIG. 5a). The 1,3dipolar cycloaddition of carbon nanotubes with azomethine ylides can be employed to equip CNs with pendants of oligoethyleneglycol bearing terminal amines for the binding and delivery of DNA plasmids ${ }^{168}$. The carboxylic groups at the tips of oxidized CNs allow the attachment of ammonium and guanidinium dendrons by amide bond formation 
or click chemistry for siRNA complexation and delivery ${ }^{169}$. In an alternate approach to covalent modification, supramolecular hydrophobic interactions between CNs and lipid/PEG amphiphiles can also be employed to stabilize $\mathrm{CNs}$ in water and functionalize them by disulfide bonds with a siRNA cargo ${ }^{170}$. As the bio-distribution of CNs is influenced by their width ${ }^{171}$ or length ${ }^{172}$, this property can be exploited in targeted gene delivery ${ }^{172}$. Recent studies have shown that CNs have the ability to insert and cross the zona pellucida to deliver DNA into embryos without the requirement of individual manipulation ${ }^{173}$. Cationic fullerenes, such as the tetra(piperazino)fullerene epoxide, can efficiently condense and deliver a plasmid DNA with suitable low toxicity when used in vivo ${ }^{174}$. Polycationic fullerene hexakis-adducts have also been employed in plasmid transfection in vitro ${ }^{175}$. The ROS generation of fullerenes when excited by light can also be exploited to enhance the endosomal escape of siRNA for cationic dextran decorated fullerene vehicles ${ }^{176}$. Conjugation of CPPs to graphene oxide nanosheets reduces CPP toxicity and increases their activity for delivering pDNA and ASO, but not siRNA ${ }^{177}$. Nanodiamonds, a potentially more biocompatible carbon allotrope, can also be complexed to nucleic acids when decorated with amines ${ }^{178}$ or cationic polymers $^{179-181}$ (FIG. 5b). The polymer pendants can be covalently attached by reaction with the carboxylated diamond surface ${ }^{179}$ or non-covalently conjugated by the electrostatic interactions between the cationic polymer and the anionic oxidized nanodiamond ${ }^{180,181}$.

Metal Nanoparticles. The precise control of size, shape and the responsiveness to external stimuli are examples of the critical features that metal nanoparticles offer for biomedical applications. Additionally, the surface of metal particles can be straightforwardly functionalized with different bioactive and biocompatible targeting molecules. The thiol-gold linkage constitutes a simple and reliable method for the functionalization and modification of gold nanoparticles (FIG. 5c). Tissue-targeting of siRNA was achieved by the thiol-gold connection of metal nanoparticles and a block copolymer shell of poly-L-lysine-poly-ethylenglycol terminated by cyclic RGD peptides ${ }^{182}$ (FIG. 5c, left). The embedding of gold nanoparticles in hydrogels has been applied for colon cancer treatments by triplecombination therapy (siRNA, drug and phototherapy). This multifunctional approach involved gold nanorods decorated with the Avastin antibody drug against VEGF and the colorectal cancer targeting peptide TCP-1. The nanorods were combined with gold nanospheres that were covered with siRNA and further functionalized with endosomolytic peptides for improved release ${ }^{183}$. Gold nanoclusters, prepared by glutathione and oligoarginine controlled $\mathrm{Au}^{3+}$ reduction, have been recently confirmed as excellent siRNA delivery vehicles for silencing the NGF gene against the challenging pancreatic cancer ${ }^{184}$ (FIG. 5c, middle).

Spherical Nucleic Acids. The tightly packing of nucleic acids over the surface of nanoparticles gives rise to spherical shaped nucleic acids conjugates (SNAs) with interesting properties such as increased stability, enhanced affinity and the ability to transfect cells despite their negative surface charge due to potential interaction with scavenger receptors ${ }^{185}$. Different SNAs with gold cores have been used for the delivery of siRNA ${ }^{186-188}$ (FIG. 5c, right) or ribozymes $^{189}$ into cells and animals. Topical wound application of SNAs made of oligoethylene glycol and siRNA (against GM3S) restores wound healing in diabetic mice ${ }^{186}$. SNAs surface modification with nuclear localization signal peptides (NLS) strongly enhanced nuclei siRNA delivery and induced long term gene silencing by RNAdirected DNA methylation ${ }^{188}$. Although SNAs were initially assembled on gold nanoparticles ${ }^{185}$, further studies confirmed that their emerging properties were independent from the metal core. These findings triggered the emergence of more biocompatible cores such as DNA ${ }^{190}$, polymers $\left(\mathrm{HOPO}^{191}\right)$, liposomes ${ }^{192}$ or other structures $\left(\mathrm{POSS}^{193}\right)$. These “organic” SNAs have been successfully tested in siRNA delivery ${ }^{190-193}$.

Porous particles. Mesoporous silica nanoparticles can achieve an extremely high siRNA loading capacity of up to $380 \mu \mathrm{g} / \mathrm{mg}^{194}$. Such porous nanoparticles can be grafted with silanes (APTES, TEOS, MPTES) to modify their surface with amino and mercapto-groups (FIG. 5d). siRNA was then loaded by incubation in solution at low pH and the particles were finally covered with a block copolymer that was further modified with hydrophobic oleic pendants and terminal cysteines for cross-linking. The final silicon based porous ensemble achieved one of the highest siRNA delivery efficiencies described for silica nanoparticles ${ }^{194}$. A similar porous silicon platform can also be functionalized with aminopropyl-triethoxysilane (APTES), followed by amide connection with L-arginine and PEI. The pores of the cationic silicon carrier were loaded with siRNA, which was released in the form of polyplexes after silicon degradation. The prolonged slow release of these polyplexes reduced the toxicity of the formulation after systemic injection ${ }^{195}$. APTES grafted silica nanoparticles can be also functionalized by coordination with $\mathrm{Ce}^{3+}$ for further anchoring of branched PEI polymer. The resulting nanoparticles (SPA-Ce-PEI) delivered siRNA with higher efficiency than branched PEI alone ${ }^{196}$. Anionic mesoporous silicon nanoparticles, decorated with ICP (3isocyanatopropyltriethoxysilane), can be covered with cyclodextrin-grafted polyethylenimine. Doxorubicin was then encapsulated in the porous nanomaterial and the resulting nanoparticles were applied to the delivery of a cytotoxic drug and a siRNA against PKM2 in combined therapy against orthotopic breast tumours ${ }^{197}$. Metal organic frameworks (MOFs) constitute promising scaffolds for nucleotide encapsulation and delivery due to their controlled porosity. $\mathrm{Zr}^{4+}$ based MOFs were applied in combined therapy for the co-delivery of a cis-platin pro-drug and a 
siRNA ${ }^{198}$. In a similar strategy, cysteine grafted MOFs were filled with Se or Ru because of their ability to disrupt microtubules and act as antitumour agents. These MOFs were also loaded with VEGF siRNA by the coordination of the vacant $\mathrm{Fe}(\mathrm{III})$ sites with the nucleotide phosphates. The final nanoparticles were applied for combined therapy against multidrug resistance breast cancer cells ${ }^{199}$ (FIG. 5d).
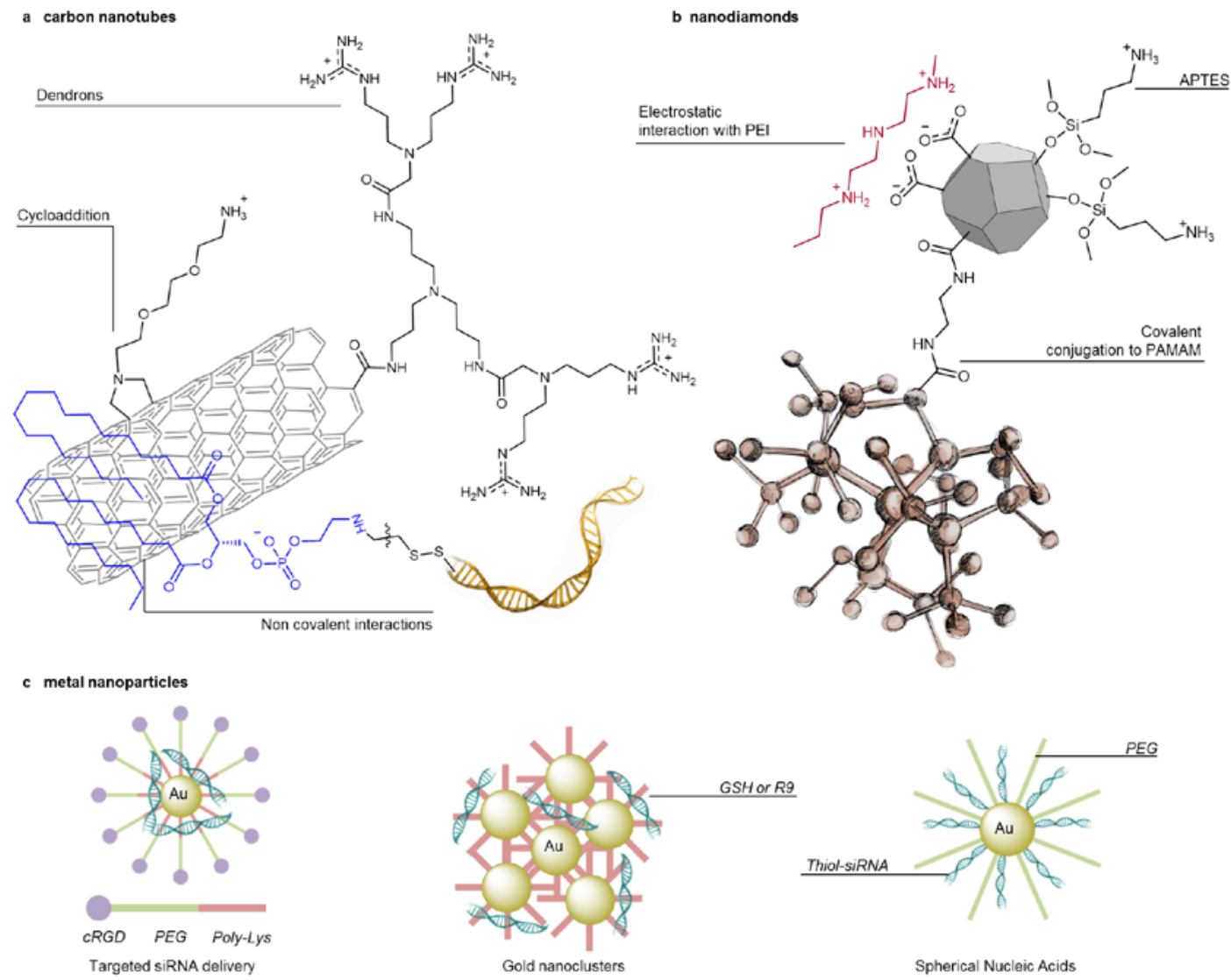

d porous nanoparticles
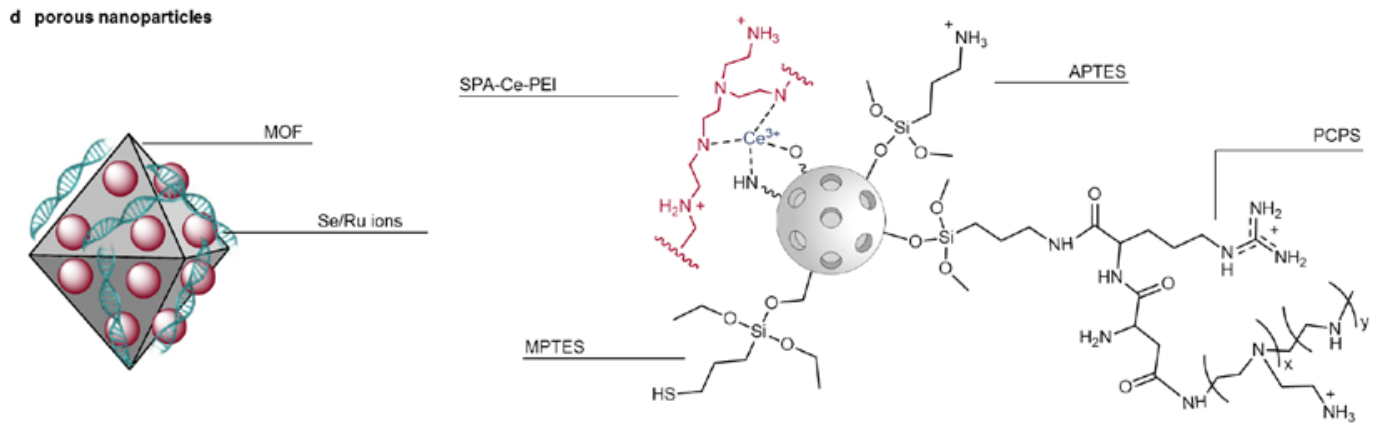

Figure 5. Nanoparticles for gene delivery. a) Covalent and non covalent modifications of carbon nanotubes for the delivery of nucleic acids. b) Surface functionalization of nanodiamonds for nucleic acid interactions. c) Delivery systems involving gold nanoparticles: a gold nanoparticle modified with a targeting motif (cRGD), PEG and polylysine for siRNA binding ${ }^{182}$; gold nanoclusters formed by reduction in the presence of glutathione and oligoarginine ${ }^{184}$ and an example of spherical nucleic acids ${ }^{186}$, in which siRNA is bound to the nanoparticle through a thiol group and decorated with PEG; d) Porous nanoparticles. Left: Metal-organic framework (MIL-101) incorporating Se or Ru ions for microtubule disruption and siRNA. Right: Surface functionalization of mesoporous silica nanoparticles. Coordination via Cerium of PEI (SPA-Ce-PEI), engraftment with APTES, or further modification of APTES with arginine and PEI to generate PCPS (polycation-functionalized nanoporous silicon) to obtain the positive charge necessary for nucleic acids interaction, or introduction of thiol groups with MPTES for crosslinking with other polymers. 


\section{Discussion and outlook}

525 The increasingly active field of non-viral gene delivery holds great promise for the future of biotechnology and human health. The improvement of the synthetic methods has recently granted the access to new encouraging molecular entities and nucleotide modifications such as phosphotriesters ${ }^{48}$ or guanidiniocarbonylpyrrole groups ${ }^{101}$. Furthermore, the recent advances in microscopy and cell biology have allowed a higher level of understanding of the highly dynamic mechanism of uptake and escape of the cargo. These and other advances continuously assist and push chemists and material scientists to design and develop the next generation of non-viral carriers that can be sensitive to critical stimuli such as the specific $\mathrm{pH}$ required for disassembly ${ }^{132}$ or the optimal $\mathrm{pK}_{\mathrm{a}}$ of the lipid nanoparticles surface for enhanced uptake ${ }^{115}$.

A clear trend for the future of the field will be the combination of new materials with novel formulation techniques. By blurring the barriers between different categories, the strength of each material can compensate the weakness of its counterpart and thus improve the performance of the final functional composite. Endosomolytic peptides buried in pH-sensitive micelles ${ }^{134}$, polymer-coated silica nanoparticles ${ }^{194}$ or peptide-lipid hybrids ${ }^{98}$ are just a few recent examples that outline potential directions of the field. Additionally, combined therapy emerges as an encouraging strategy in where the nucleic acid function is supplemented with other therapeutics such as bioactive polymers ${ }^{157}$ and co-delivery of cytotoxic agents ${ }^{197}$. Furthermore, the still mostly unexplored combination of chemically modified nucleotides and the next generation of synthetic transporters constitute a promising strategy to tackle the future challenges of synthetic materials at the forefront of gene delivery. Combinatorial libraries and high-throughput screening also constitutes an important and complementary technique compared to rational design, as it can identify

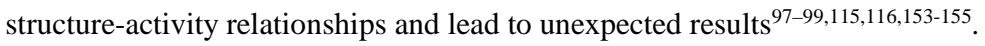

Importantly, the synthesis and formulation of the nanocarriers has to be scalable, reproducible and stable and although the field strongly demands new conceptual designs and strategies, the transference of these technologies to therapeutic applications will require a careful consideration of the synthetic scaling up process. In lipid particles, film hydration is sensitive to organic contaminants and in batch ethanol dilution homogeneous mixing is hard to achieve. Therefore, crossflow or microfluidics constitutes an excellent alternative for reproducibility and scalability ${ }^{107,109,112-}$ 118,123. The standard electrostatic complexation of nucleotides with polymers or peptides requires a good control of mixing and thus concentrations, charge ratios and $\mathrm{pH}$ and ionic strength have to be carefully considered ${ }^{94,95,97-102,130-}$ 133,136,145,146. Polyplex stability upon dilution is lower than for other formulations, although PEGylation might improve this situation. In gold nano-conjugates, salt reduction followed by ligand exchange or direct reduction with thiolated ligands can be potentially scaled up ${ }^{182-184,186-188}$. However, the election of the method in this case, will depend on the availability of the suitable thiolated ligands. Silica nanoparticles seem also promising scalable materials as they can be prepared by condensation of inexpensive silicates under different conditions ${ }^{194-197}$.

It seems nowadays clear that not all in vitro results will work in vivo. Most of the in vitro experiments have been done in serum free conditions on immortalized cell lines that usually contain alterations that affect their ability to detect nucleic acids and enhance the cells tolerance to stress. These critical points for in vitro studies could lead to an overestimation of the delivery efficiency and an underestimation of the vehicle toxicity. Better in vitro models, such as primary cell cultures ${ }^{77,136,138}$, or spheroids ${ }^{80,146}$ may predict better the outcome of in vivo experiments, but they still lack the complexity of a living organism. In addition, the translation of these results to the clinic will always have to pass regulatory challenges, as all new formulations must be proven safe before further testing, and in this regard, formulations related to well established technologies, such as lipid-based carriers, will be in an advantageous position. So far, the most advanced methods in the race for clinical application ${ }^{34}$ of non-viral vectors are phosphorothioates, naked plasmid DNA, lipid-based carriers and, to a lesser extent, polymeric carriers ${ }^{34-38}$, which have already some examples approved ${ }^{35}$ or nearly approved ${ }^{38}$ for human use. The simplicity of the method of delivery of the naked cargo and the strong experience with liposomal-based drug delivery vehicles justify their predominance. On the other hand, non-biodegradable nanoparticles (i.e. carbon nanotubes, fullerenes, metal nanoparticles, etc.) may be problematic in the long-term, especially in cases where repeated administration may be necessary, as they tend to accumulate in liver and kidneys. To address this concern, there are several initiatives that try to replace the metal core of SNAs for biocompatible alternatives ${ }^{190-193}$. However, it is also possible that the therapeutic use of non-biodegradable nanoparticles might be restricted to cases in which the nature of the particle contributes to the treatment, as in photothermal therapy ${ }^{183}$.

Despite impressive advances in the last decade, there are still considerable challenges that need to be met to help broaden the scope of potential future therapeutic applications of non-viral vectors such as vehicle bioavailability ${ }^{79-81}$, reduction of immune response $\mathrm{e}^{32,74}$, balance of stability and release $\mathrm{u}^{40-42,58,78,115}$ and endosomal escape $\mathrm{e}^{95,132,135}$. In this regard, the growing number of synthetic materials for the efficient in vivo transfection of hard-to-transfect cells 
demonstrates the enormous power of chemistry and biology working together (TABLE 4). All these great advances 579 help inspire new approaches to gene therapy and bring hope for the future of human health ${ }^{165}$. 


\begin{tabular}{|c|c|c|c|c|c|c|c|}
\hline Vector & Particle size & $\begin{array}{l}\text { Serum } \\
\text { Stability }\end{array}$ & Tolerability & Capacity & Scalability & Targeting & In vivo application* \\
\hline $\begin{array}{l}\text { Self-delivering } \\
\text { oligonucleotides }\end{array}$ & $\begin{array}{l}\text { PS-tcDNA: } 40-100 \\
\mathrm{~nm}\end{array}$ & $\begin{array}{l}\text { Variable } \\
\text { depending on } \\
\text { the } \\
\text { modifications. }\end{array}$ & $\begin{array}{l}\text { Potential problems by unwanted } \\
\text { protein interactions. }\end{array}$ & $\begin{array}{l}\text { Limited by the synthetic } \\
\text { method; typically short. }\end{array}$ & $\begin{array}{l}\text { Yes, but modified } \\
\text { nucleotides } \\
\text { increase costs. }\end{array}$ & $\begin{array}{l}\text { Yes, by attaching } \\
\text { ligands. }\end{array}$ & Some approved for human use ${ }^{35,41}$ \\
\hline Physical methods & $\begin{array}{l}\text { Delivery of the } \\
\text { naked cargo. } \\
\text { Microbubbles ( 2- } \\
7 \mu \mathrm{m}) \text { and } \\
\text { liposomes ( 100- } \\
200 \mathrm{~nm})\end{array}$ & $\begin{array}{l}\text { For } \\
\text { liposomes, > } \\
30 \text { min. }\end{array}$ & $\begin{array}{l}\text { For ultasound targeted } \\
\text { microbubble disruption, potential } \\
\text { liver damage. } \\
\text { With degradable nanoneedles, } \\
\text { less inflammation than with } \\
\text { classical nanoneedles. }\end{array}$ & From ASO/siRNA to pDNA. & Yes & $\begin{array}{l}\text { Local administration } \\
\text { with nanoneedles, or } \\
\text { spatial control through } \\
\text { target directed } \\
\text { ultrasounds. }\end{array}$ & $\begin{array}{l}\text { Transfection of skin and muscle of } \\
\text { mice with nanoneedles }{ }^{67} \text {. } \\
\text { Transfection with ultrasound in } \\
\text { mice }{ }^{68-70} \\
\text { Potential ex vivo applications for } \\
\text { microfluidic systems }{ }^{66}\end{array}$ \\
\hline $\begin{array}{l}\text { Protein based } \\
\text { methods }\end{array}$ & $\begin{array}{l}\text { For VLPs, depends } \\
\text { on the virus used. } \\
\text { In other cases, } \\
\text { soluble. }\end{array}$ & $\begin{array}{l}\text { Increased } \\
\text { stability. }\end{array}$ & Low toxicity & $\begin{array}{l}\text { Depends on the protein used: } \\
\text { in viral capsid, several } \\
\text { kilobases, for dsRNA binding } \\
\text { proteins and modified } \\
\text { oligonucleotides, short } \\
\text { sequences. }\end{array}$ & $\begin{array}{l}\text { Potential } \\
\text { limitations by } \\
\text { protein } \\
\text { purification. }\end{array}$ & $\begin{array}{l}\text { By viral tropism, } \\
\text { targeting ligands, by } \\
\text { fusion to antibodies or } \\
\text { by EPR (albumin). }\end{array}$ & $\begin{array}{l}\text { i.v. }^{73,79-83} \text { and intranasal }{ }^{77} \\
\text { inoculation in mice. }\end{array}$ \\
\hline Peptides & $\begin{array}{l}50 \mathrm{~nm} \text { to several } \\
\mu \mathrm{m} \text { (fibers). }\end{array}$ & $\begin{array}{l}\text { Several days } \\
\text { in serum. }\end{array}$ & From low to moderately toxic. & $\begin{array}{l}\text { From ASO/siRNA to pDNA. } \\
\text { In peptide-oligonucleotide } \\
\text { conjugates, length is limited } \\
\text { by the synthetic method. }\end{array}$ & $\begin{array}{l}\text { Yes, but in some } \\
\text { cases synthesis } \\
\text { can be expensive. }\end{array}$ & $\begin{array}{l}\text { With targeting } \\
\text { sequences or ligands. }\end{array}$ & $\begin{array}{l}\text { i.c. }{ }^{91}, \text { i.v. }{ }^{86,94} \text {, and intradermal }{ }^{95} \\
\text { injection of mice. } \\
\text { i.v., i.c. or i.m. in dogs }{ }^{87}\end{array}$ \\
\hline Lipid-based & $50-400 \mathrm{~nm}$ & $\begin{array}{l}\text { Variable } \\
\text { depending on } \\
\text { nanoparticle } \\
\text { composition }\end{array}$ & $\begin{array}{l}\text { Low toxicity, except for highly } \\
\text { cationic particles. }\end{array}$ & From ASO/siRNA to pDNA. & $\begin{array}{l}\text { Yes, although } \\
\text { procedures that } \\
\text { require sonication } \\
\text { can be hard to } \\
\text { scale up. }\end{array}$ & $\begin{array}{l}\text { By EPR or with } \\
\text { targeting ligands. }\end{array}$ & $\begin{array}{l}\text { i.v. }{ }^{115-117} \text {, s.c. }{ }^{118} \text { and combined with } \\
\text { hydrogels }^{2128} \text { in mice; lipid } \\
\text { nanoparticles in clinical trials }\end{array}$ \\
\hline $\begin{array}{l}\text { Polymers, } \\
\text { dendrimers and } \\
\text { micelles }\end{array}$ & $\begin{array}{l}\text { From } 10 \mathrm{~nm} \\
\text { (smallest } \\
\text { dendrimers) to } \\
\text { almost } 1 \mu \mathrm{m} \text { (fibers } \\
\text { and large } \\
\text { polyplexes). } \\
\text { Typically 50-300 } \\
\mathrm{nm}\end{array}$ & Several hours & $\begin{array}{l}\text { Most polymers are very } \\
\text { biocompatible, but some toxicity } \\
\text { issues have been observed } \\
\text { (immune response, } \\
\text { cytotoxicity...) }\end{array}$ & From ASO/siRNA to pDNA. & $\begin{array}{l}\text { Yes, although } \\
\text { some of the more } \\
\text { complex } \\
\text { formulations can } \\
\text { be challenging. }\end{array}$ & $\begin{array}{l}\text { By EPR, with targeting } \\
\text { ligands or stimuli } \\
\text { responsive motifs. }\end{array}$ & 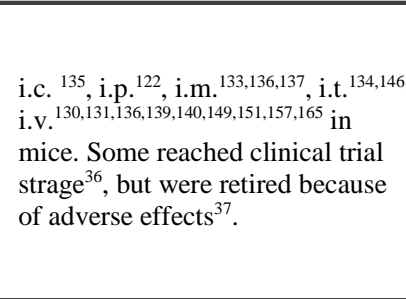 \\
\hline Nanoparticles & $\begin{array}{l}\text { From } 20 \mathrm{~nm} \\
\text { (SNAs) to } 60 \mu \mathrm{m} \\
\text { (CNs) }\end{array}$ & $\begin{array}{l}\text { From hours to } \\
\text { days }\end{array}$ & $\begin{array}{l}\text { In general, inert and with low } \\
\text { toxicity, but hard to degrade in } \\
\text { the body. Some carbon allotropes } \\
\text { can be toxic depending on } \\
\text { functionalization and } \\
\text { contaminants from synthesis. }\end{array}$ & From ASO/siRNA to pDNA. & $\begin{array}{l}\text { Yes, but } \\
\text { influenced by the } \\
\text { modifications. }\end{array}$ & $\begin{array}{l}\text { With targeting ligands, } \\
\text { EPR, size... in some } \\
\text { cases light stimulation. }\end{array}$ & $\begin{array}{l}\text { i.v. }{ }^{172,174,184,195,197,199} \text {, s.c. }{ }^{176} \text { or } \\
\text { topically in mice } e^{186} \text {; bovine } \\
\text { embryo transfection }{ }^{173} \text {. }\end{array}$ \\
\hline
\end{tabular}

Table 4. A brief summary of the different categories discussed on the text. * i.c.: intracranial, s.c.: subcutaneous, i.p.: intraperitoneal, i.m.: intramuscular, i.v.: intravenous. 
583 This work was partially supported by the Spanish Agencia Estatal de Investigación (AEI) [CTQ2014-59646-R, SAF2017-89890-R], the Xunta de Galicia (ED431G/09, ED431C 2017/25 and 2016-AD031) and the ERDF. J.M.

585 received a Ramón y Cajal (RYC-2013-13784), an ERC Starting Investigator Grant (DYNAP-677786) and a Young Investigator Grant from the Human Frontier Science Research Program (RGY0066/2017).

587 
1. Matteucci, M. D. \& Caruthers, M. H. Synthesis of deoxyoligonucleotides on a polymer support. J. Am. Chem. Soc. 103, 3185-3191 (1981).

2. Saiki, R. K. et al. Primer-directed enzymatic amplification of DNA with a thermostable DNA polymerase. Science 239, 487-91 (1988).

3. Hutchison, C. A. et al. Mutagenesis at a specific position in a DNA sequence. J. Biol. Chem. 253, 6551-6560 (1978).

4. Heim, R. \& Tsien, R. Y. Engineering green fluorescent protein for improved brightness, longer wavelengths and fluorescence resonance energy transfer. Curr. Biol. 6, 178-182 (1996).

5. Barbas, C. F., Kang, A. S., Lerner, R. A. \& Benkovic, S. J. Assembly of combinatorial antibody libraries on phage surfaces: the gene III site. Proc. Natl. Acad. Sci. U. S. A. 88, 7978-82 (1991).

6. Wang, L., Brock, A., Herberich, B. \& Schultz, P. G. Expanding the genetic code of Escherichia coli. Science 292, 498-500 (2001).

7. Lerner, R. A., Benkovic, S. J. \& Schultz, P. G. At the crossroads of chemistry and immunology: catalytic antibodies. Science 252, 659-67 (1991).

8. Siegel, J. B. et al. Computational Design of an Enzyme Catalyst for a Stereoselective Bimolecular Diels-Alder Reaction. Science 329, 309-313 (2010).

9. Wang, L. et al. Synthetic Genomics: From DNA Synthesis to Genome Design. Angew. Chem. Int. Ed. Engl. 57, 1748-1756 (2018).

10. Gibson, D. G. et al. Creation of a Bacterial Cell Controlled by a Chemically Synthesized Genome. Science 329, 52-56 (2010).

11. Annaluru, N. et al. Total synthesis of a functional designer eukaryotic chromosome. Science 344, 55-8 (2014).

12. Naldini, L. Gene therapy returns to centre stage. Nature 526, 351-360 (2015).

13. Dunbar, C. E. et al. Gene therapy comes of age. Science 359, eaan4672 (2018).

14. Sheridan, C. Gene therapy finds its niche. Nat. Biotechnol. 29, 459-459 (2011).

15. Jenks, S. Gene therapy death--"everyone has to share in the guilt". J. Natl. Cancer Inst. 92, 98-100 (2000).

16. Wang, T., Upponi, J. R. \& Torchilin, V. P. Design of multifunctional non-viral gene vectors to overcome physiological barriers: Dilemmas and strategies. Int. J. Pharm. 427, 3-20 (2012).

17. Juliano, R. L. The delivery of therapeutic oligonucleotides. Nucleic Acids Res. 44, 65186548 (2016).

18. Yin, H. et al. Non-viral vectors for gene-based therapy. Nat. Rev. Genet. 15, 541-555 (2014).

19. Hill, A. B., Chen, M., Chen, C. K., Pfeifer, B. A. \& Jones, C. H. Overcoming gene-delivery hurdles: Physiological considerations for nonviral vectors. Trends Biotechnol. 34, 91- 
105 (2016).

20. Giacca, M. \& Zacchigna, S. Virus-mediated gene delivery for human gene therapy. J. Control. Release 161, 377-388 (2012).

21. Merten, O.-W. \& Gaillet, B. Viral vectors for gene therapy and gene modification approaches. Biochem. Eng. J. 108, 98-115 (2016).

22. Melchiorri, D. et al. Regulatory evaluation of Glybera in Europe - two committees, one mission. Nat. Rev. Drug Discov. 12, 719 (2013).

23. Peng, Z. Current status of gendicine in China: recombinant human Ad-p53 agent for treatment of cancers. Hum. Gene Ther. 16, 1016-27 (2005).

24. Russell, S. et al. Efficacy and safety of voretigene neparvovec (AAV2-hRPE65v2) in patients with RPE65-mediated inherited retinal dystrophy: a randomised, controlled, open-label, phase 3 trial. Lancet 390, 849-860 (2017).

25. Kaiser, J. A second chance. Science 358, 582-585 (2017).

26. Senior, M. After Glybera's withdrawal, what's next for gene therapy? Nat. Biotechnol. 35, 491-492 (2017).

27. Hajj, K. A. \& Whitehead, K. A. Tools for translation: non-viral materials for therapeutic mRNA delivery. Nat. Rev. Mater. 2, 17056 (2017).

28. Kaczmarek, J. C., Kowalski, P. S. \& Anderson, D. G. Advances in the delivery of RNA therapeutics: from concept to clinical reality. Genome Med. 9, 60 (2017).

29. Reichmuth, A. M., Oberli, M. A., Jaklenec, A., Langer, R. \& Blankschtein, D. mRNA vaccine delivery using lipid nanoparticles. Ther. Deliv. 7, 319-334 (2016).

30. Stanton, M. G. Current Status of Messenger RNA Delivery Systems. Nucleic Acid Ther. 28, 158-165 (2018).

31. Hartung, T. \& Daston, G. Are in vitro tests suitable for regulatory use? Toxicol. Sci. 111, 233-237 (2009).

32. Khvorova, A. \& Watts, J. K. The chemical evolution of oligonucleotide therapies of clinical utility. Nat. Biotechnol. 35, 238-248 (2017).

33. Kumar, S. R., Markusic, D. M., Biswas, M., High, K. A. \& Herzog, R. W. Clinical development of gene therapy: results and lessons from recent successes. Mol. Ther. Methods Clin. Dev. 3, 16034 (2016).

34. Ginn, S. L., Amaya, A. K., Alexander, I. E., Edelstein, M. \& Abedi, M. R. Gene therapy clinical trials worldwide to 2017: An update. J. Gene Med. 20, e3015 (2018).

35. Stein, C. A. \& Castanotto, D. FDA-Approved Oligonucleotide Therapies in 2017. Mol. Ther. 25, 1069-1075 (2017).

36. Zuckerman, J. E. \& Davis, M. E. Clinical experiences with systemically administered siRNA-based therapeutics in cancer. Nat. Rev. Drug Discov. 14, 843-56 (2015).

37. Barata, P., Sood, A. K. \& Hong, D. S. RNA-targeted therapeutics in cancer clinical trials: Current status and future directions. Cancer Treat. Rev. 50, 35-47 (2016). 
38. Adams, D. \& Ole, S. Patisiran, an investigational RNAi therapeutic for patients with hereditary transthyretin-mediated (hATTR) amyloidosis: Results from the phase 3 APOLLO study. Rev. Neurol. (Paris). 174, S37 (2018).

39. Stein, C. A. et al. Efficient gene silencing by delivery of locked nucleic acid antisense oligonucleotides, unassisted by transfection reagents. Nucleic Acids Res. 38, e3 (2010).

40. Goyenvalle, A. et al. Functional correction in mouse models of muscular dystrophy using exon-skipping tricyclo-DNA oligomers. Nat. Med. 21, 270-5 (2015).

41. Geary, R. S., Baker, B. F. \& Crooke, S. T. Clinical and Preclinical Pharmacokinetics and Pharmacodynamics of Mipomersen (Kynamro $\left.{ }^{\circledR}\right)$ : A Second-Generation Antisense Oligonucleotide Inhibitor of Apolipoprotein B. Clin. Pharmacokinet. 54, 133-146 (2015).

42. Souleimanian, N. et al. Antisense 2'-deoxy, 2'-fluoroarabino nucleic acid (2'F-ANA) oligonucleotides: In vitro gymnotic silencers of gene expression whose potency is enhanced by Fatty Acids. Mol. Ther. - Nucleic Acids 1, 1-9 (2012).

43. Azad, R. F., Brown-Driver, V., Buckheit, R. W. \& Anderson, K. P. Antiviral activity of a phosphorothioate oligonucleotide complementary to human cytomegalovirus RNA when used in combination with antiviral nucleoside analogs. Antiviral Res. 28, 101-111 (1995).

44. Chi, X., Gatti, P. \& Papoian, T. Safety of antisense oligonucleotide and siRNA-based therapeutics. Drug Discov. Today 22, 823-833 (2017).

45. Shen, W. et al. Acute hepatotoxicity of 2' fluoro-modified 5-10-5 gapmer phosphorothioate oligonucleotides in mice correlates with intracellular protein binding and the loss of DBHS proteins. Nucleic Acids Res. 46, 2204-2217 (2018).

46. Burdick, A. D. et al. Sequence motifs associated with hepatotoxicity of locked nucleic acid-modified antisense oligonucleotides. Nucleic Acids Res. 42, 4882-4891 (2014).

47. Fuertes, A., Juanes, M., Granja, J. R. \& Montenegro, J. Supramolecular functional assemblies: dynamic membrane transporters and peptide nanotubular composites. Chem. Commun. 53, 7861-7871 (2017).

48. Meade, B. R. et al. Efficient delivery of RNAi prodrugs containing reversible chargeneutralizing phosphotriester backbone modifications. Nat. Biotechnol. 32, 1256-1261 (2014).

49. McNamara, J. O. et al. Cell type-specific delivery of siRNAs with aptamer-siRNA chimeras. Nat. Biotechnol. 24, 1005-1015 (2006).

50. Shu, D. et al. Systemic Delivery of Anti-miRNA for Suppression of Triple Negative Breast Cancer Utilizing RNA Nanotechnology. ACS Nano 9, 9731-9740 (2015).

51. Ren, K. et al. A DNA dual lock-and-key strategy for cell-subtype-specific siRNA delivery. Nat. Commun. 7, 13580 (2016).

52. Schmidt, K. et al. Characterizing the effect of GalNAc and phosphorothioate backbone on binding of antisense oligonucleotides to the asialoglycoprotein receptor. Nucleic Acids Res. 45, 2294-2306 (2017).

53. Tanowitz, M. et al. Asialoglycoprotein receptor 1 mediates productive uptake of $\mathrm{N}$ - 
acetylgalactosamine-conjugated and unconjugated phosphorothioate antisense oligonucleotides into liver hepatocytes. Nucleic Acids Res. 45, 12388-12400 (2017).

54. Zlatev, I. et al. Reversal of siRNA-mediated gene silencing in vivo. Nat. Biotechnol. 36, (2018).

55. Huang, Y. Preclinical and Clinical Advances of GalNAc-Decorated Nucleic Acid Therapeutics. Mol. Ther. - Nucleic Acids 6, 116-132 (2017).

56. Lu, X. et al. Effective Antisense Gene Regulation via Noncationic, Polyethylene Glycol Brushes. J. Am. Chem. Soc. 138, 9097-9100 (2016).

57. Jia, F. et al. Depth-Profiling the Nuclease Stability and the Gene Silencing Efficacy of Brush-Architectured Poly(ethylene glycol)-DNA Conjugates. J. Am. Chem. Soc. 139, 10605-10608 (2017).

58. Jin, Y. et al. Biodegradable, multifunctional DNAzyme nanoflowers for enhanced cancer therapy. NPG Asia Mater. 9, e365 (2017).

59. Lee, J. H. et al. Rolling circle transcription-based polymeric siRNA nanoparticles for tumor-targeted delivery. J. Control. Release 263, 29-38 (2017).

60. Rozema, D. B. et al. Protease-triggered siRNA delivery vehicles. J. Control. Release 209, 57-66 (2015).

61. Lee, $\mathrm{K}$. et al. In vivo delivery of transcription factors with multifunctional oligonucleotides. Nat. Mater. 14, 701-706 (2015).

62. McCaffrey, J., Donnelly, R. F. \& McCarthy, H. O. Microneedles: an innovative platform for gene delivery. Drug Deliv. Transl. Res. 5, 424-437 (2015).

63. Suda, T. \& Liu, D. Hydrodynamic gene delivery: Its principles and applications. Mol. Ther. 15, 2063-2069 (2007).

64. Stewart, M. P. et al. In vitro and ex vivo strategies for intracellular delivery. Nature 538, 183-192 (2016).

65. Markey, P. M. et al. Driving CAR T-cells forward. Nat. Rev. Clin. Oncol. 6, 300-308 (2015).

66. Ding, X. et al. High-throughput nuclear delivery and rapid expression of DNA via mechanical and electrical cell-membrane disruption. Nat. Biomed. Eng. 1, 0039 (2017).

67. Chiappini, C. et al. Biodegradable silicon nanoneedles delivering nucleic acids intracellularly induce localized in vivo neovascularization. Nat. Mater. 14, 532-539 (2015).

68. Anderson, C. D., Moisyadi, S., Avelar, A., Walton, C. B. \& Shohet, R. V. Ultrasoundtargeted hepatic delivery of factor IX in hemophiliac mice. Gene Ther. 23, 510-519 (2016).

69. Manta, S. et al. Cationic microbubbles and antibiotic-free miniplasmid for sustained ultrasound-mediated transgene expression in liver. J. Control. Release 262, 170-181 (2017).

70. Chertok, B., Langer, R. S. \& Anderson, D. G. Spatial Control of Gene Expression by 
Nanocarriers Using Heparin Masking and Ultrasound-Targeted Microbubble Destruction. ACS Nano 10, 7267-7278 (2016).

71. Yoon, S., Wang, P., Peng, Q., Wang, Y. \& Shung, K. K. Acoustic-transfection for genomic manipulation of single-cells using high frequency ultrasound. Sci. Rep. 7, 5275 (2017).

72. Pastuzyn, E. D. et al. The Neuronal Gene Arc Encodes a Repurposed Retrotransposon Gag Protein that Mediates Intercellular RNA Transfer. Cell 172, 275-288.e18 (2018).

73. Chen, L. S. et al. Efficient gene transfer using the human JC virus-like particle that inhibits human colon adenocarcinoma growth in a nude mouse model. Gene Ther. 17, 1033-1041 (2010).

74. Lee, P. W. et al. Polymer Structure and Conformation Alter the Antigenicity of Virus-like Particle-Polymer Conjugates. J. Am. Chem. Soc. 139, 3312-3315 (2017).

75. Zackova Suchanova, J., Neburkova, J., Spanielova, H., Forstova, J. \& Cigler, P. Retargeting Polyomavirus-Like Particles to Cancer Cells by Chemical Modification of Capsid Surface. Bioconjug. Chem. 28, 307-313 (2017).

76. Tong, G. J., Hsiao, S. C., Carrico, Z. M. \& Francis, M. B. Viral Capsid DNA Aptamer Conjugates as Multivalent Cell-Targeting Vehicles. J. Am. Chem. Soc. 131, 11174-11178 (2009).

77. Eguchi, A. et al. Efficient siRNA Delivery into Primary Cells by Peptide TransductiondsRNA Binding Domain (PTD-DRBD) Fusion Protein. Nat. Biotechnol. 27, 567-571 (2009).

78. Yang, N. J. et al. Cytosolic delivery of siRNA by ultra-high affinity dsRNA binding proteins. Nucleic Acids Res. 45, 7602-7614 (2017).

79. Bienk, K. et al. An albumin-mediated cholesterol design-based strategy for tuning siRNA pharmacokinetics and gene silencing. J. Control. Release 232, 143-151 (2016).

80. Sarett, S. M. et al. Lipophilic siRNA targets albumin in situ and promotes bioavailability, tumor penetration, and carrier-free gene silencing. Proc. Natl. Acad. Sci. U. S. A. 114, E6490-E6497 (2017).

81. Hvam, M. L. et al. Fatty Acid-Modified Gapmer Antisense Oligonucleotide and Serum Albumin Constructs for Pharmacokinetic Modulation. Mol. Ther. 25, 1710-1717 (2017).

82. Song, E. et al. Antibody mediated in vivo delivery of small interfering RNAs via cellsurface receptors. Nat. Biotechnol. 23, 709-717 (2005).

83. Cuellar, T. L. et al. Systematic evaluation of antibody-mediated siRNA delivery using an industrial platform of THIOMAB-siRNA conjugates. Nucleic Acids Res. 43, 1189-1203 (2015).

84. Lehto, T., Ezzat, K., Wood, M. J. A. \& El Andaloussi, S. Peptides for nucleic acid delivery. Adv. Drug Deliv. Rev. 106, 172-182 (2016).

85. Tai, W. \& Gao, X. Functional peptides for siRNA delivery. Adv. Drug Deliv. Rev. 110-111, 157-168 (2017).

86. Hammond, S. M. et al. Systemic peptide-mediated oligonucleotide therapy improves long-term survival in spinal muscular atrophy. Proc. Natl. Acad. Sci. U. S. A. 113, 10962- 
87. Echigoya, Y. et al. Effects of systemic multiexon skipping with peptide-conjugated morpholinos in the heart of a dog model of Duchenne muscular dystrophy. Proc. Natl. Acad. Sci. 114, 4213-4218 (2017).

88. Medina, S. H. et al. An Intrinsically Disordered Peptide Facilitates Non-Endosomal Cell Entry. Angew. Chemie - Int. Ed. 55, 3369-3372 (2016).

89. Soudah, T., Mogilevsky, M., Karni, R. \& Yavin, E. CLIP6-PNA-Peptide Conjugates: NonEndosomal Delivery of Splice Switching Oligonucleotides. Bioconjug. Chem. 28, 30363042 (2017).

90. Bulut, S. et al. Slow release and delivery of antisense oligonucleotide drug by selfassembled peptide amphiphile nanofibers. Biomacromolecules 12, 3007-3014 (2011).

91. Mazza, M., Hadjidemetriou, M., De Lázaro, I., Bussy, C. \& Kostarelos, K. Peptide nanofiber complexes with siRNA for deep brain gene silencing by stereotactic neurosurgery. ACS Nano 9, 1137-1149 (2015).

92. Yolamanova, M. et al. Peptide nanofibrils boost retroviral gene transfer and provide a rapid means for concentrating viruses. Nat. Nanotechnol. 8, 130-136 (2013).

93. Dai, B. et al. Tunable assembly of amyloid-forming peptides into nanosheets as a retrovirus carrier. Proc. Natl. Acad. Sci. 112, 2996-3001 (2015).

94. McCarthy, H. O. et al. Development and characterization of self-assembling nanoparticles using a bio-inspired amphipathic peptide for gene delivery. J. Control. Release 189, 141-9 (2014).

95. Udhayakumar, V. K. et al. Arginine-Rich Peptide-Based mRNA Nanocomplexes Efficiently Instigate Cytotoxic $T$ Cell Immunity Dependent on the Amphipathic Organization of the Peptide. Adv. Healthc. Mater. 6, 1601412 (2017).

96. Douat, C. et al. A cell-penetrating foldamer with a bioreducible linkage for intracellular delivery of DNA. Angew. Chem. Int. Ed. Engl. 54, 11133-11137 (2015).

97. Gehin, C. et al. Dynamic Amphiphile Libraries To Screen for the "Fragrant" Delivery of siRNA into HeLa Cells and Human Primary Fibroblasts. J. Am. Chem. Soc. 135, 92959298 (2013).

98. Louzao, I., García-Fandiño, R. \& Montenegro, J. Hydrazone-modulated peptides for efficient gene transfection. J. Mater. Chem. B 5, 4426-4434 (2017).

99. Lostalé-Seijo, I., Louzao, I., Juanes, M. \& Montenegro, J. Peptide/Cas9 nanostructures for ribonucleoprotein cell membrane transport and gene edition. Chem. Sci. 8, 79237931 (2017).

100. Li, M. et al. Incorporation of a Non-Natural Arginine Analogue into a Cyclic Peptide Leads to Formation of Positively Charged Nanofibers Capable of Gene Transfection. Angew. Chemie Int. Ed. 55, 598-601 (2016).

101. Li, M., Schlesiger, S., Knauer, S. K. \& Schmuck, C. A Tailor-Made Specific Anion-Binding Motif in the Side Chain Transforms a Tetrapeptide into an Efficient Vector for Gene Delivery. Angew. Chemie - Int. Ed. 54, 2941-2944 (2015). 
102. Montenegro, J., Ghadiri, M. R. \& Granja, J. R. Ion channel models based on selfassembling cyclic peptide nanotubes. Acc. Chem. Res. 46, 2955-65 (2013).

103. Jana, P. et al. Efficient Gene Transfection through Inhibition of $\beta$-Sheet (Amyloid Fiber) Formation of a Short Amphiphilic Peptide by Gold Nanoparticles. Angew. Chemie - Int. Ed. 56, 8083-8088 (2017).

104. Freire, J. M. et al. siRNA-cell-penetrating peptides complexes as a combinatorial therapy against chronic myeloid leukemia using BV173 cell line as model. J. Control. Release 245, 127-136 (2017).

105. Felgner, P. L. et al. Lipofection: a highly efficient, lipid-mediated DNA-transfection procedure. Proc. Natl. Acad. Sci. 84, 7413-7417 (1987).

106. Allen, T. M. \& Cullis, P. R. Liposomal drug delivery systems: From concept to clinical applications. Adv. Drug Deliv. Rev. 65, 36-48 (2013).

107. Oude Blenke, E. E., van den Dikkenberg, J., van Kolck, B., Kros, A. \& Mastrobattista, E. Coiled coil interactions for the targeting of liposomes for nucleic acid delivery. Nanoscale 8, 8955-8965 (2016).

108. Yang, J. et al. Drug Delivery via Cell Membrane Fusion Using Lipopeptide Modified Liposomes. ACS Cent. Sci. 2, 621-630 (2016).

109. O'Brien, P. J., Elahipanah, S., Rogozhnikov, D. \& Yousaf, M. N. Bio-Orthogonal Mediated Nucleic Acid Transfection of Cells via Cell Surface Engineering. ACS Cent. Sci. 3, 489-500 (2017).

110. Kauffman, K. J. et al. Optimization of Lipid Nanoparticle Formulations for mRNA Delivery in Vivo with Fractional Factorial and Definitive Screening Designs. Nano Lett. 15, 7300-7306 (2015).

111. Farhood, H., Serbina, N. \& Huang, L. The role of dioleoyl phosphatidylethanolamine in cationic liposome mediated gene transfer. Biochim. Biophys. Acta-Biomembr. 1235, 289-295 (1995).

112. Leal, C., Bouxsein, N. F., Ewert, K. K. \& Safinya, C. R. Highly Efficient Gene Silencing Activity of siRNA Embedded in a Nanostructured Gyroid Cubic Lipid Matrix. J. Am. Chem. Soc. 132, 16841-16847 (2010).

113. Kim, H. \& Leal, C. Cuboplexes: Topologically Active siRNA Delivery. ACS Nano 9, 1021410226 (2015).

114. Evers, M. J. W. et al. State-of-the-Art Design and Rapid-Mixing Production Techniques of Lipid Nanoparticles for Nucleic Acid Delivery. Small Methods 1700375 (2018). doi:10.1002/smtd.201700375

115. Whitehead, K. A. et al. Degradable lipid nanoparticles with predictable in vivo siRNA delivery activity. Nat. Commun. 5, 4277 (2014).

116. Viricel, W. et al. Cationic switchable lipids: pH-triggered molecular switch for siRNA delivery. Nanoscale 9, 31-36 (2017).

117. Kranz, L. M. et al. Systemic RNA delivery to dendritic cells exploits antiviral defence for cancer immunotherapy. Nature 534, 396-401 (2016). 
118. Oberli, M. A. et al. Lipid Nanoparticle Assisted mRNA Delivery for Potent Cancer Immunotherapy. Nano Lett. 17, 1326-1335 (2017).

119. Liang, C. et al. Aptamer-functionalized lipid nanoparticles targeting osteoblasts as a novel RNA interference-based bone anabolic strategy. Nat. Med. 21, 288-294 (2015).

120. Ripoll, M. et al. pH-Responsive Nanometric Polydiacetylenic Micelles Allow for Efficient Intracellular siRNA Delivery. ACS Appl. Mater. Interfaces 8, 30665-30670 (2016).

121. Morin, E., Nothisen, M., Wagner, A. \& Remy, J. S. Cationic polydiacetylene micelles for gene delivery. Bioconjug. Chem. 22, 1916-1923 (2011).

122. Neuberg, P. et al. Polydiacetylenic nanofibers as new siRNA vehicles for in vitro and in vivo delivery. Nanoscale 10, 1587-1590 (2018).

123. Jayaraman, M. et al. Maximizing the potency of siRNA lipid nanoparticles for hepatic gene silencing in vivo. Angew. Chemie - Int. Ed. 51, 8529-8533 (2012).

124. Yim, N. et al. Exosome engineering for efficient intracellular delivery of soluble proteins using optically reversible protein-protein interaction module. Nat. Commun. 7, 12277 (2016).

125. Lee, J. J. et al. Cellular Engineering with Membrane Fusogenic Liposomes to Produce Functionalized Extracellular Vesicles. ACS Appl. Mater. Interfaces 8, 6790-6795 (2016).

126. O'Loughlin, A. J. et al. Functional Delivery of Lipid-Conjugated siRNA by Extracellular Vesicles. Mol. Ther. 25, 1580-1587 (2017).

127. Didiot, M.-C. et al. Exosome-mediated Delivery of Hydrophobically Modified siRNA for Huntingtin mRNA Silencing. Mol. Ther. 24, 1836-1847 (2016).

128. Cui, Z.-K. et al. Delivery of siRNA via cationic Sterosomes to enhance osteogenic differentiation of mesenchymal stem cells. J. Control. Release 217, 42-52 (2015).

129. Wang, Y. et al. A nanoparticle-based strategy for the imaging of a broad range of tumours by nonlinear amplification of microenvironment signals. Nat. Mater. 13, 204212 (2014).

130. Xu, X. et al. Ultra-pH-Responsive and Tumor-Penetrating Nanoplatform for Targeted siRNA Delivery with Robust Anti-Cancer Efficacy. Angew. Chemie - Int. Ed. 55, 70917094 (2016).

131. Xu, X. et al. Multifunctional Envelope-Type siRNA Delivery Nanoparticle Platform for Prostate Cancer Therapy. ACS Nano 11, 2618-2627 (2017).

132. Zhou, J. et al. PH-Sensitive Nanomicelles for High-Efficiency siRNA Delivery in Vitro and in Vivo: An Insight into the Design of Polycations with Robust Cytosolic Release. Nano Lett. 16, 6916-6923 (2016).

133. Chiper, M., Tounsi, N., Kole, R., Kichler, A. \& Zuber, G. Self-aggregating 1.8 kDa polyethylenimines with dissolution switch at endosomal acidic $\mathrm{pH}$ are delivery carriers for plasmid DNA, mRNA, siRNA and exon-skipping oligonucleotides. J. Control. Release 246, 60-70 (2017).

134. Cheng, Y., Yumul, R. C. \& Pun, S. H. Virus-Inspired Polymer for Efficient In Vitro and In Vivo Gene Delivery. Angew. Chem. Int. Ed. Engl. 55, 12013-7 (2016). 
135. Cheng, Y. et al. Development of switchable polymers to address the dilemma of stability and cargo release in polycationic nucleic acid carriers. Biomaterials 127, 89-96 (2017).

136. McKinlay, C. J. et al. Charge-altering releasable transporters (CARTs) for the delivery and release of mRNA in living animals. Proc. Natl. Acad. Sci. 114, E448-E456 (2017).

137. Chahal, J. S. et al. Dendrimer-RNA nanoparticles generate protective immunity against lethal Ebola, H1N1 influenza, and Toxoplasma gondii challenges with a single dose. Proc. Natl. Acad. Sci. 113, E4133-E4142 (2016).

138. Liu, S. et al. Bioreducible Zinc(II)-Coordinative Polyethylenimine with Low Molecular Weight for Robust Gene Delivery of Primary and Stem Cells. J. Am. Chem. Soc. 139, 5102-5109 (2017).

139. Zou, Y. et al. Virus-Mimicking Chimaeric Polymersomes Boost Targeted Cancer siRNA Therapy In Vivo. Adv. Mater. 29, 1-8 (2017).

140. Li, L. et al. Artificial Virus Delivers CRISPR-Cas9 System for Genome Editing of Cells in Mice. ACS Nano 11, 95-111 (2017).

141. Naito, M. et al. A phenylboronate-functionalized polyion complex micelle for ATPtriggered release of siRNA. Angew. Chemie - Int. Ed. 51, 10751-10755 (2012).

142. Naito, M. et al. Enhanced Intracellular Delivery of siRNA by Controlling ATPResponsivity of Phenylboronic Acid-Functionalized Polyion Complex Micelles. Macromol. Biosci. 18, 1700357 (2018).

143. Yoshinaga, N. et al. Polyplex Micelles with Phenylboronate/Gluconamide Cross-Linking in the Core Exerting Promoted Gene Transfection through Spatiotemporal Responsivity to Intracellular pH and ATP Concentration. J. Am. Chem. Soc. 139, 18567-18575 (2017).

144. Truong, N. P. et al. An influenza virus-inspired polymer system for the timed release of siRNA. Nat. Commun. 4, 1902 (2013).

145. Wang, M., Liu, H., Li, L. \& Cheng, Y. A fluorinated dendrimer achieves excellent gene transfection efficacy at extremely low nitrogen to phosphorus ratios. Nat. Commun. 5, 3053 (2014).

146. Wang, H. et al. Self-Assembled Fluorodendrimers Combine the Features of Lipid and Polymeric Vectors in Gene Delivery. Angew. Chemie - Int. Ed. 54, 11647-11651 (2015).

147. Wang, L.-H., Wu, D.-C., Xu, H.-X. \& You, Y.-Z. High DNA-Binding Affinity and GeneTransfection Efficacy of Bioreducible Cationic Nanomicelles with a Fluorinated Core. Angew. Chemie Int. Ed. 55, 755-759 (2016).

148. Zhang, Z. et al. The fluorination effect of fluoroamphiphiles in cytosolic protein delivery. Nat. Commun. 9, 1377 (2018).

149. Davis, M. E. The First Targeted Delivery of siRNA in Humans via a Nanoparticle : From Concept to Clinic. Mol. Pharm. 6, 659-668 (2009).

150. Maity, S., Choudhary, P., Manjunath, M., Kulkarni, A. \& Murthy, N. A biodegradable adamantane polymer with ketal linkages in its backbone for gene therapy. Chem. Commun. 51, 15956-15959 (2015).

151. Chen, X., Qiu, Y.-K., Owh, C., Loh, X. J. \& Wu, Y.-L. Supramolecular cyclodextrin 
nanocarriers for chemo- and gene therapy towards the effective treatment of drug resistant cancers. Nanoscale 8, 18876-18881 (2016).

152. Eldredge, A. C., Johnson, M. E., Oldenhuis, N. J. \& Guan, Z. Focused Library Approach to Discover Discrete Dipeptide Bolaamphiphiles for siRNA Delivery. Biomacromolecules 17, 3138-3144 (2016).

153. Yan, Y. et al. Functional polyesters enable selective siRNA delivery to lung cancer over matched normal cells. Proc. Natl. Acad. Sci. 113, E5702-E5710 (2016).

154. Hao, J. et al. Rapid Synthesis of a Lipocationic Polyester Library via Ring-Opening Polymerization of Functional Valerolactones for Efficacious siRNA Delivery. J. Am. Chem. Soc. 137, 9206-9209 (2015).

155. Priegue, J. M. et al. In Situ Functionalized Polymers for siRNA Delivery. Angew. Chemie Int. Ed. 55, 7492-7495 (2016).

156. Priegue, J. M. et al. Different-Length Hydrazone Activated Polymers for Plasmid DNA Condensation and Cellular Transfection. Biomacromolecules acs.biomac.8b00252 (2018). doi:10.1021/acs.biomac.8b00252

157. Zhao, Y. et al. PolyMetformin combines carrier and anticancer activities for in vivo siRNA delivery. Nat. Commun. 7, 11822 (2016).

158. Lyu, Y. et al. Dendronized Semiconducting Polymer as Photothermal Nanocarrier for Remote Activation of Gene Expression. Angew. Chemie - Int. Ed. 56, 9155-9159 (2017).

159. Tan, Z., Dhande, Y. K. \& Reineke, T. M. Cell Penetrating Polymers Containing Guanidinium Trigger Apoptosis in Human Hepatocellular Carcinoma Cells unless Conjugated to a Targeting N-Acetyl-Galactosamine Block. Bioconjug. Chem. 28, 29852997 (2017).

160. Liu, Y., Wenning, L., Lynch, M. \& Reineke, T. M. New poly(D-glucaramidoamine)s induce DNA nanoparticle formation and efficient gene delivery into mammalian cells. J. Am. Chem. Soc. 126, 7422-7423 (2004).

161. Dong, Y. et al. Poly(glycoamidoamine) Brushes Formulated Nanomaterials for Systemic siRNA and mRNA Delivery in Vivo. Nano Lett. 16, 842-848 (2016).

162. Kaczmarek, J. C. et al. Polymer-Lipid Nanoparticles for Systemic Delivery of mRNA to the Lungs. Angew. Chemie - Int. Ed. 55, 13808-13812 (2016).

163. Li, J. et al. Structurally Programmed Assembly of Translation Initiation Nanoplex for Superior mRNA Delivery. ACS Nano 11, 2531-2544 (2017).

164. Hong, C. A. et al. Dendrimeric siRNA for Efficient Gene Silencing. Angew. Chem. Int. Ed. Engl. 54, 6740-4 (2015).

165. Smith, T. T. et al. In situ programming of leukaemia-specific T cells using synthetic DNA nanocarriers. Nat. Nanotechnol. 12, 813-820 (2017).

166. Graham, F. L. L. \& van der Eb, A. J. J. A new technique for the assay of infectivity of human adenovirus 5 DNA. Virology 52, 456-67 (1973).

167. Hong, G., Diao, S., Antaris, A. L. \& Dai, H. Carbon Nanomaterials for Biological Imaging and Nanomedicinal Therapy. Chem. Rev. 115, 10816-10906 (2015). 
168. Pantarotto, D. et al. Functionalized carbon nanotubes for plasmid DNA gene delivery. Angew. Chem. Int. Ed. Engl. 43, 5242-6 (2004).

169. Battigelli, A. et al. Ammonium and guanidinium dendron-carbon nanotubes by amidation and click chemistry and their use for siRNA delivery. Small 9, 3610-3619 (2013).

170. Kam, N. W. S., Liu, Z. \& Dai, H. Functionalization of carbon nanotubes via cleavable disulfide bonds for efficient intracellular delivery of siRNA and potent gene silencing. J. Am. Chem. Soc. 127, 12492-12493 (2005).

171. Wang, J. T. W. et al. The relationship between the diameter of chemicallyfunctionalized multi-walled carbon nanotubes and their organ biodistribution profiles in vivo. Biomaterials 35, 9517-9528 (2014).

172. Cifuentes-Rius, A. et al. In Vivo Fate of Carbon Nanotubes with Different Physicochemical Properties for Gene Delivery Applications. ACS Appl. Mater. Interfaces 9, 11461-11471 (2017).

173. Munk, M. et al. Efficient delivery of DNA into bovine preimplantation embryos by multiwall carbon nanotubes. Sci. Rep. 6, 33588 (2016).

174. Maeda-Mamiya, R. et al. In vivo gene delivery by cationic tetraamino fullerene. Proc. Natl. Acad. Sci. 107, 5339-5344 (2010).

175. Sigwalt, D. et al. Gene delivery with polycationic fullerene hexakis-adducts. Chem. Commun. 47, 4640-2 (2011).

176. Wang, J. et al. Visible light-switched cytosol release of siRNA by amphiphilic fullerene derivative to enhance RNAi efficacy in vitro and in vivo. Acta Biomater. 59, 158-169 (2017).

177. Dowaidar, M., Abdelhamid, H. N., Hällbrink, M., Zou, X. \& Langel, Ü. Graphene oxide nanosheets in complex with cell penetrating peptides for oligonucleotides delivery. Biochim. Biophys. Acta - Gen. Subj. 1861, 2334-2341 (2017).

178. Chu, Z. et al. Rapid endosomal escape of prickly nanodiamonds: implications for gene delivery. Sci. Rep. 5, 11661 (2015).

179. Lim, D. G. et al. Polyamidoamine-Decorated Nanodiamonds as a Hybrid Gene Delivery Vector and siRNA Structural Characterization at the Charged Interfaces. ACS Appl. Mater. Interfaces 9, 31543-31556 (2017).

180. Zhang, X. Q. et al. Polymer-functionalized nanodiamond platforms as vehicles for gene delivery. ACS Nano 3, 2609-2616 (2009).

181. Chen, M. et al. Nanodiamond vectors functionalized with polyethylenimine for siRNA delivery. J. Phys. Chem. Lett. 1, 3167-3171 (2010).

182. Yi, Y. et al. Targeted systemic delivery of siRNA to cervical cancer model using cyclic RGD-installed unimer polyion complex-assembled gold nanoparticles. J. Control. Release 244, 247-256 (2016).

183. Conde, J., Oliva, N., Zhang, Y. \& Artzi, N. Local triple-combination therapy results in tumour regression and prevents recurrence in a colon cancer model. Nat. Mater. 15, 
184. Lei, Y. et al. Gold nanoclusters-assisted delivery of NGF siRNA for effective treatment of pancreatic cancer. Nat. Commun. 8, 15130 (2017).

185. Cutler, J. I., Auyeung, E. \& Mirkin, C. A. Spherical nucleic acids. J. Am. Chem. Soc. 134, 1376-1391 (2012).

186. Randeria, P. S. et al. siRNA-based spherical nucleic acids reverse impaired wound healing in diabetic mice by ganglioside GM3 synthase knockdown. Proc. Natl. Acad. Sci. U. S. A. 112, 5573-5578 (2015).

187. Sita, T. L. et al. Dual bioluminescence and near-infrared fluorescence monitoring to evaluate spherical nucleic acid nanoconjugate activity in vivo. Proc. Natl. Acad. Sci. 114, 4129-4134 (2017).

188. Li, N. et al. Nuclear-targeted siRNA delivery for long-term gene silencing. Chem. Sci. 8, 2816-2822 (2017).

189. Rouge, J. L. et al. Ribozyme-Spherical Nucleic Acids. J. Am. Chem. Soc. 137, 1052810531 (2015).

190. Ruan, W. et al. DNA nanoclew templated spherical nucleic acids for siRNA delivery. Chem. Commun. 54, 3609-3612 (2018).

191. Calabrese, C. M. et al. Biocompatible infinite-coordination-polymer nanoparticlenucleic-acid conjugates for antisense gene regulation. Angew. Chem. Int. Ed. Engl. 54, 476-480 (2015).

192. Banga, R. J., Chernyak, N., Narayan, S. P., Nguyen, S. T. \& Mirkin, C. A. Liposomal spherical nucleic acids. J. Am. Chem. Soc. 136, 9866-9869 (2014).

193. Li, H. et al. Molecular spherical nucleic acids. Proc. Natl. Acad. Sci. U. S. A. 115, 43404344 (2018).

194. Möller, K. et al. Highly efficient siRNA delivery from core-shell mesoporous silica nanoparticles with multifunctional polymer caps. Nanoscale 8, 4007-4019 (2016).

195. Shen, J. et al. High Capacity Nanoporous Silicon Carrier for Systemic Delivery of Gene Silencing Therapeutics. ACS Nano 7, 9867-9880 (2013).

196. Kapilov-Buchman, Y., Lellouche, E., Michaeli, S. \& Lellouche, J. P. Unique surface modification of silica nanoparticles with polyethylenimine (PEI) for siRNA delivery using cerium cation coordination chemistry. Bioconjug. Chem. 26, 880-889 (2015).

197. Shen, J. et al. Multi-step encapsulation of chemotherapy and gene silencing agents in functionalized mesoporous silica nanoparticles. Nanoscale 9, 5329-5341 (2017).

198. He, C., Lu, K., Liu, D. \& Lin, W. Nanoscale metal-organic frameworks for the co-delivery of cisplatin and pooled siRNAs to enhance therapeutic efficacy in drug-resistant ovarian cancer cells. J. Am. Chem. Soc. 136, 5181-5184 (2014).

199. Chen, Q. et al. Se/Ru-Decorated Porous Metal-Organic Framework Nanoparticles for the Delivery of Pooled siRNAs to Reversing Multidrug Resistance in Taxol-Resistant Breast Cancer Cells. ACS Appl. Mater. Interfaces 9, 6712-6724 (2017). 
1070

200. Thierry, A. R. et al. Characterization of liposome-mediated gene delivery: Expression, stability and pharmacokinetics of plasmid DNA. Gene Ther. 4, 226-237 (1997).

201. Tsui, N. B. Y., Ng, E. K. O. \& Lo, Y. M. D. Stability of endogenous and added RNA in blood specimens, serum, and plasma. Clin. Chem. 48, 1647-1653 (2002).

202. Sahin, U., Karikó, K. \& Türeci, Ö. mRNA-based therapeutics - developing a new class of drugs. Nat. Rev. Drug Discov. 13, 759-780 (2014).

203. Layzer, J. M. et al. In vivo activity of nuclease-resistant siRNAs. RNA 10, 766-71 (2004). 
1073

1074

1075

1076

1077

1078

1079

1080

1081

1082

1083

1084

1085

1086

1087

1088

1089

1090

1091

1092

1093

1094

1095

1096

1097

1098

1099

1100

1101

1102

1103

1104

1105

1106

1107

1108

1109

1110

1111

1112

1113

Khvorova, A. \& Watts, J. K. The chemical evolution of oligonucleotide therapies of clinical utility. Nat. Biotechnol. 35, 238-248 (2017).

*This review provides a comprehensive overview of the chemical modification of oligonucleotides of medical interest.

Meade, B. R. et al. Efficient delivery of RNAi prodrugs containing reversible charge-neutralizing phosphotriester backbone modifications. Nat. Biotechnol. 32, 1256-1261 (2014).

*This study presents a method for the efficient production of phosphotriester nucleic acid derivatives with excellent targeting and delivery properties.

Lee, K. et al. In vivo delivery of transcription factors with multifunctional oligonucleotides. Nat. Mater. 14, 701-706 (2015).

*This paper presents a procedure for the delivery of transcription factors using oligonucleotides modified with $\mathrm{pH}$ responsive constructs.

Li, M., Schlesiger, S., Knauer, S. K. \& Schmuck, C. A Tailor-Made Specific Anion-Binding Motif in the Side Chain Transforms a Tetrapeptide into an Efficient Vector for Gene Delivery. Angew. Chemie Int. Ed. 54, 2941-2944 (2015).

* This article introduces the new guanidinocarbonyl pyrrole group for nucleic acids delivery.

O’Brien, P. J., Elahipanah, S., Rogozhnikov, D. \& Yousaf, M. N. Bio-Orthogonal Mediated Nucleic Acid Transfection of Cells via Cell Surface Engineering. ACS Cent. Sci. 3, 489-500 (2017).

* This study describes a method for the application of bio-orthogonal chemistry to the fusion of liposomes.

Lee, J. J. et al. Cellular Engineering with Membrane Fusogenic Liposomes to Produce Functionalized Extracellular Vesicles. ACS Appl. Mater. Interfaces 8, 6790-6795 (2016).

* In this article, a versatile method for the chemical functionalization of exosomes is described.

Zhou, J. et al. PH-Sensitive Nanomicelles for High-Efficiency siRNA Delivery in Vitro and in Vivo: An Insight into the Design of Polycations with Robust Cytosolic Release. Nano Lett. 16, 6916-6923 (2016).

* This article focuses on the properties required to maximize release in conditions of very low uptake.

McKinlay, C. J. et al. Charge-altering releasable transporters (CARTs) for the delivery and release of mRNA in living animals. Proc. Natl. Acad. Sci. 114, E448-E456 (2017).

* This study describes a self-immolative polymer that is able to deliver mRNA in primary cells and in vivo.

Smith, T. T. et al. In situ programming of leukaemia-specific T cells using synthetic DNA nanocarriers. Nat. Nanotechnol. 12, 813-820 (2017).

* In this article, a method for the in situ modification of T-cells for cancer immunotherapy is shown.

Li, N. et al. Nuclear-targeted siRNA delivery for long-term gene silencing. Chem. Sci. 8, 28162822 (2017).

* This paper shows the impact that subcellular distribution of the cargo has in the duration of the silencing. 